\title{
A Review on the Complementarity Modelling in Competitive Electricity Markets
}

\author{
Christos N. Dimitriadis, Evangelos G. Tsimopoulos and Michael C. Georgiadis * D
}

Department of Chemical Engineering, School of Engineering, Aristotle University of Thessaloniki, P.O. Box 455, 54124 Thessaloniki, Greece; cdimitria@cheng.auth.gr (C.N.D.); vtsimopoulos@gmail.com (E.G.T.)

* Correspondence: mgeorg@auth.gr

Citation: Dimitriadis, C.N.;

Tsimopoulos, E.G.; Georgiadis, M.C. A Review on the Complementarity Modelling in Competitive Electricity Markets. Energies 2021, 14, 7133. https://doi.org/10.3390/en14217133

Academic Editors: Javier Reneses and Attilio Converti

Received: 4 August 2021

Accepted: 22 October 2021

Published: 1 November 2021

Publisher's Note: MDPI stays neutral with regard to jurisdictional claims in published maps and institutional affiliations.

Copyright: (c) 2021 by the authors. Licensee MDPI, Basel, Switzerland. This article is an open access article distributed under the terms and conditions of the Creative Commons Attribution (CC BY) license (https:// creativecommons.org/licenses/by/ $4.0 /)$.

\begin{abstract}
In recent years, the ever-increasing research interest in various aspects of the electricity pool-based markets has generated a plethora of complementarity-based approaches to determine participating agents' optimal offering/bidding strategies and model players' interactions. In particular, the integration of multiple and diversified market agents, such as conventional generation companies, renewable energy sources, electricity storage facilities and agents with a mixed generation portfolio has instigated significant competition, as each player attempts to establish their market dominance and realize substantial financial benefits. The employment of complementarity modelling approaches can also prove beneficial for the optimal coordination of the electricity and natural gas market coupling. Linear and nonlinear programming as well as complementarity modelling, mainly in the form of mathematical programs with equilibrium constraints (MPECs), equilibrium programs with equilibrium constraints (EPECs) and conjectural variations models (CV) have been widely employed to provide effective market clearing mechanisms, enhance agents' decision-making process and allow them to exert market power, under perfect and imperfect competition and various market settlements. This work first introduces the theoretical concepts that regulate the majority of contemporary competitive electricity markets. It then presents a comprehensive review of recent advances related to complementarity-based modelling methodologies and their implementation in current competitive electricity pool-based markets applications.
\end{abstract}

Keywords: complementarity; electricity markets; natural gas market coupling; MPEC; EPEC; conjectural variations; electricity storage; renewable energy sources

\section{Introduction}

For almost ten decades, the electricity supply industry operated under the dominance of vertically integrated monopolies, thus restricting power output onto the market and reducing consumers' sovereignty and economic welfare. The liberalization of the electricity generation sector and the introduction of multiple agents with divergent interests brought a revolution in the electricity markets and formed the contemporary deregulated competitive regime [1]. Wholesale competition provided robust cost-minimizing incentives for suppliers, suppressed average market prices and encouraged efficient real-time pricing; ergo, it reduced electricity consumption during peak load demand time periods [2].

While current market settlements promote free competition in generation and retail mode, transmission and distribution of electricity operate under the custody of noncommercial monopolistic organizations, called Independent System Operators (ISOs). Seven system operators in the U.S. (CAISO, MISO, NYISO, ISO-NE, PJM, SPP, ERCOT) have received the Federal Energy Regulatory Commission's (FERC's) approval to regulate wholesale electric power markets in the Western, Eastern and Texas Interconnects, while in Canada, AESO and IESO oversee electricity market and ensure reliability within their corresponding territorial jurisdiction. AEMO [3], National Grid ESO and Energinet, in Australia, United Kingdom and Denmark correspondingly, complete the classification 
of some of the world's leading organizations and constitute fundamental partners of the Global Power System Transformation Consortium (G-PST), which aims at dramatically reducing pollution emissions over the next ten years, by efficiently integrating sustainable energy investments into power systems [4].

The ominous environmental challenges that emerged from climate change have designated the urgent need of adopting sustainable emission-free alternatives, such as renewable energy sources (RES), and integrated them into the existing power grids. Solar photovoltaic panels, hydropower plants, hydrogen conversion and wind turbines constitute the main exponents of clean electricity generation transition and pave the way for the electricity sector's decarbonization, with the latter one being so far the leading form of renewable technologies. As offshore wind farms nowadays are experiencing a profound growth in countries such as UK and Portugal, wave energy is also considered a valuable natural complement to wind energy [5].

Despite the critical contribution of non-dispatchable renewables in mitigating the greenhouse effect expansion, their incorporation and operational qualification in current electricity market regulatory frameworks, comprises a challenging element, due to the stochastic nature of their generation. However, implementing well-defined probabilistic forecasts can substantially enhance the decision-making process in electricity market operations, by optimally controlling the risk induced by unforeseen events [6].

Predictive analyses conducted by International Renewable Energy Agency (IRENA) illustrate that the share of renewable energy is expected to envisage an impressive increase of $61 \%$ by 2050 , accounting for $86 \%$ of global power generation [7]. To ensure the reliable and efficient integration of such large volumes of variable RES, power systems with greater and more versatile flexibility should be developed. Electricity storage plays a critical role in optimally integrating high shares of renewable energy in contemporary electricity markets, while in parallel providing a wide range of system services and additional degrees of stability in power grids [8]. Lithium-ion batteries, compressed air energy storage (CAES), pumped-hydroelectric facilities (PHS) and flywheel systems constitute some of the dominant electricity storage technologies nowadays and each one is characterized by different characteristics and applications [9]. However, the energy storage sector has to compete with a plethora of market flexibility measures such as demand response, ancillary services, smart networks and dispatchable renewable resources (biogas, power-to-gas and power-tohydrogen systems) that can efficiently manage electricity generation-consumption imbalances. In such an antagonistic framework, electricity storage technologies are constantly evolving, in order to prove quantitatively and economically competitive.

An equivalent to the electricity market deregulation process was followed for the natural gas market [10]. Natural gas is considered the cleanest burning fossil fuel and a perfect partner to the variable renewable energy sources, due to its inherent flexible and reliable characteristics and they jointly contribute to the coal and oil utilization de-escalation. Today, natural gas accounts for $25 \%$ of total energy consumption in the European Union and experiences a near $2 \%$ year-on-year increase rate, with the highest relative market shares being observed in UK and Italy, reaching up to $40 \%$ of the total power generation [11,12]. In the near future, gas power consumption is set to rise considerably, although demand will likely stabilize in the medium term [12].

Natural gas transmission system operators (TSOs) play a vital role in the expedient regulation and operation of wholesale gas markets at a national level. However, by virtue of the need for panoramic monitoring and improved coordination between these markets, organizations with a holistic range of functions have been established. The founding of the European network of transmission system operators for gas (ENTSO-G) in December 2009, constitutes a typical example. The main objectives of this organization focus on facilitating and enhancing cooperation between TSOs in the EU, ensuring the efficient operation of a pan-European gas transmission system, encouraging the formation of the internal gas market and stimulating cross-border trade. 
Traditionally, the clearing of electricity and natural gas markets constitute autonomous processes that coincide and interact through coordination parameters, predefined in a static manner, such as natural gas price and fuel consumption by gas-fired power plants (GFPPs) [13]. However, this static definition impedes the development of an accurate coordination setup that will flourish interactions between the two markets. Thus, a plethora of coordination schemes has recently been presented in the literature [14-16] to efficiently overcome the aforementioned issues and provide a feasible and well-regulated electricity and natural gas market coupling.

In recent years, a considerable number of reviews and tutorials have been proposed for the investigation of energy markets' regulatory framework, operation and modelling. The work by González et al. [17], constitutes a great example that provides significant insights on the modelling and current implementations in energy and reserve markets. The review performs a thorough classification of ancillary services in US and European electricity markets and an in-depth analysis of dispatching methods. Prabhakar Karthikeyan et al. [18] suggested a detailed overview of the research contributions related to the evolution of market power metric indices and Game Theoretic algorithms and applications in contemporary deregulated electricity market schemes, in various countries.

Ruiz et al. [19] presented a comprehensive tutorial review to designate the practicality of complementarity-based formulations in addressing optimization problems related to the participation of a single or multiple decision-makers, in energy markets. In particular, they illustrated the mathematical fundamentals and recommend solution approaches for MCP (Mixed Complementarity Problem), MPEC and EPEC algorithms and emphasize their functionality in electricity, emission, natural gas and multicommodity markets. Plenty of rigorous reviews on alternative key aspects of electricity markets have also appeared in the open literature with the key ones focusing on demand-side management [20,21], demand-response [22], virtual power plant (VPP) modelling [23], integration of solar power generation [24] and distributed generation allocation and planning [25].

This work aims at providing an analytical review on the most influential recent research contributions deploying advanced complementarity-based algorithms, to address challenging issues in today's competitive electricity pool markets. Emphasis is placed on the interpretation of research contributions investigating the current market clearing framework, as well as the optimal bidding strategies of generating agents, under an either perfect or imperfect competition regime. Investment, sizing and non-market-based unitcommitment models, as well as a systematic overview of demand response and ancillary services' functions, are beyond the scope of this review. It is also important to emphasize that a detailed quotation of current regulatory arrangements and policies is not considered in this review; rather the designation of the dominant role of complementarity modelling in solving decision-making problems considering electricity pool-based markets that allow trading of electricity in the short-run, is attempted.

The rest of this work is organized as follows. In Section 2, a comprehensive analysis of the fundamental theoretical aspects and principles regulating electricity markets is presented, including market structure, pricing mechanisms and competition. Section $3 \mathrm{com}-$ prises a concise classification of the main modelling approaches, as well as the dominant decomposition algorithms and solutions methodologies, currently employed. In Section 4, we attempt a systematic review of the implementations of complementarity-based methods in theoretical and real-life electricity and natural gas market coupling problems. Finally, Section 5, summarizes the prominent concluding remarks of this work and draws up possible future research challenges.

\section{Electricity Market Organization}

\subsection{Market Structure}

Energy markets nowadays operate in two separate trading arenas, futures and pools, to provide a holistic interchange framework and optimally manage transactions between electricity generators and consumers. Future markets are managed by for-profit organiza- 
tions and allow medium- and long-term power trading. While they illustrate significant research and practical interest, a thorough overview of their operational structure and function, as well as bilateral trading, is beyond the realm of this work. Instead, a meticulous analysis on pool-based energy markets' design and agents' interactions, is the fundamental purpose of this review.

The market operator (MO), is the independent nonprofit entity that operates poolbased energy markets and handles short-term transactions, namely generation and demand quotes coupling and market prices settling [26]. The day-ahead market is predominantly characterized as the main marketplace for energy transactions and is organized as a twosided auction, where market participants (producers, consumers, retailers) submit their corresponding energy and demand blocks, as well as their price offers/bids, one day in advance. Adjustment (intraday) and balancing (real-time) markets successively, constitute the necessary actions to prevent unwanted deviations and balance the power system's operation [27]. In particular, balancing markets deal with last-minute energy schedule clutters and cover dispatched power, that due to equipment failures and the stochastic nature of renewable energy sources does not materialize. Transmission congestions and load deviations also constitute key factors that justify the crucial contribution of the balancing stage to well-regulated electricity markets' operation.

Apart from energy markets, some countries have established reserve capacity markets to further guarantee the sufficient supply of balancing power throughout the power system's real-time operation. Reserve capacity provision can be determined by two means, sequentially and simultaneously. In the first case, a series of auctions subsequent to the day-ahead energy market clearing, takes place, so that unsuccessfully placed capacity, to be offered in the following auctions. In the latter case, a single coupled auction is proposed, by employing co-optimizing algorithms. Producers participating in that type of market, are compensated according to the available capacity. It is worth noting that the majority of market frameworks, also provide long-term clearing services through financial contracts, such as options, forwards and derivatives. However, an extended examination of these terms is beyond the purview of this work.

\subsection{Pricing and Bidding Mechanisms}

In organized pool-based power markets, two principal mechanisms for the determination of wholesale prices are embraced. In the absence of transmission congestion, the resulting power price is identical for all locations and set by the marginal cost offer of the most expensive generating asset. On the contrary, when power network congestion takes place, various locational marginal prices (LMPs) for each system's node emerge, due to line losses, and nodal pricing is adopted [28]. Significant benefits, such as several operational characteristics and explicit price incentives for the establishment of new investments and demand response, render LMP-based markets the preferred approach for the majority of well-regulated electricity pools. While alternative approaches exist-with the principal one dictating a single price across the network and the handling of congestion cost as a separate uplift charge-their application is considered insufficient, due to their inefficiency in hedging long-term contracts and their unpredictable nature [29].

The endorsement of the appropriate auction design in electricity spot markets constitutes a fundamental decision for the constitution of a well-configurated market framework and depends on several factors. The sealed-bid auction format, where each buyer/seller submits its offers/bids anonymously and without having knowledge of the rest of the agents' offering strategies, comprises two primary pricing mechanism approaches, uniform and pay-as-bid (or discriminatory). The uniform pricing rule entails that all generators receive an identical market-clearing price, set by the highest priced resource nominated to provide supply and is particularly popular in the US ISO markets. Conversely, in a pay-as-bid auction setup, prices paid to the dispatching generators are based on their actual offers, rather than the offer of the most expensive supplier selected for energy provision. As a result of paying winning suppliers at a distinct price, depending on their individual 
bids, pay-as-bid auctions are also called discriminatory auctions. Electricity markets of England and Wales constitute nowadays the main ground of their application.

As supported by numerous analyses, while small deviations may emerge due to market design, organization, and setting factors, market prices are unlikely to substantially differ between these auction formats. Furthermore, the literature cannot audaciously support a verdict that a pay-as-bid auction will generate lower overall prices in competitive electricity markets [30].

\subsection{Competition}

Particular emphasis has been placed on the design of energy markets in such a way, as to create an environment conducive to the enhancement of competition [2]. Unlike a monopolistic market, under a perfectly competitive energy market regime, prices are dictated by generation and demand equilibrium and firms act as price takers, having a small market share and inconsiderable impact against the "invisible hand" of the market. Under this market environment, companies whose bids deviate from clearing prices are ignored and replaced by antagonistic firms. Although perfect competition seems to promote significant social concepts, it is considered a purely theoretical construct, thus its real-life implementation in energy markets is considered utopian.

If instead, prices are not defined by supply and demand, and firms compete for their market share, attempting to exert market power and influence the clearing price outcomes through their actions, the market experiences imperfect competition. Stackelberg's single leader-follower game constitutes the main expression of imperfect competition in energy markets, and unlike other game-theoretic models, embodies a significant asymmetry between the antagonistic firms [31]. The leading firm, acting strategically and using its knowledge on the inverse demand curve, anticipates followers' decisions and manipulates market prices, either by physical or financial withholding.

\section{Electricity Markets Modelling}

The field of modelling electricity markets has received considerable attention over the past few years. A plethora of mathematical approaches has been proposed to address several aspects of energy markets, however, in the context of this review only the methodologies employed to handle problems related to the market-clearing process, as well as games of single or multiple leaders, will be presented. It is important to emphasize that this review is not an analytical mathematical tutorial, as is the case with references [19,32]. Thus, a concise illustration of the basic complementarity modelling principles is attempted, in order to facilitate the understanding of the rest of this review.

\subsection{Perfect Competition}

Perfect competition in electricity markets is usually formulated as single-level twostage stochastic programming, with the first stage involving day-ahead optimal energy dispatch and generating LMPs as dual variables. Equivalently, the second stage derives real-time market dispatch and prices, while the various sources of uncertainty are handled through the realization of multiple plausible scenarios. The objective function of the energy market clearing problem aims at the maximization of social welfare, as depicted in Figure 1. The addition of binary variables that capture specific market operations or agents' decisions, such as (dis)charging function for energy storage systems (ESSs), transforms the existing problem into a mixed-integer program (MIP).



Figure 1. Market clearing problem. 


\subsection{Imperfect Competition-Single Leader-Single Follower Games}

The strategic behavior of a generating agent can be mathematically captured through bi-level modelling and optimization frameworks, where the upper-level problem allows the agent to optimally determine its profit-maximizing offering/bidding strategy. The lower-level problem represents ISO's market-clearing procedure and yields pool prices as dual variables, as illustrated in Figure 2. In the case of a two-stage market structure, where both day-ahead and balancing market are investigated, two distinct clearing mechanisms can be employed, that is, simultaneous and sequential. While electricity markets are currently organized sequentially, both approaches have drawn significant attention in the recent literature.

\section{Bi-level formulation}

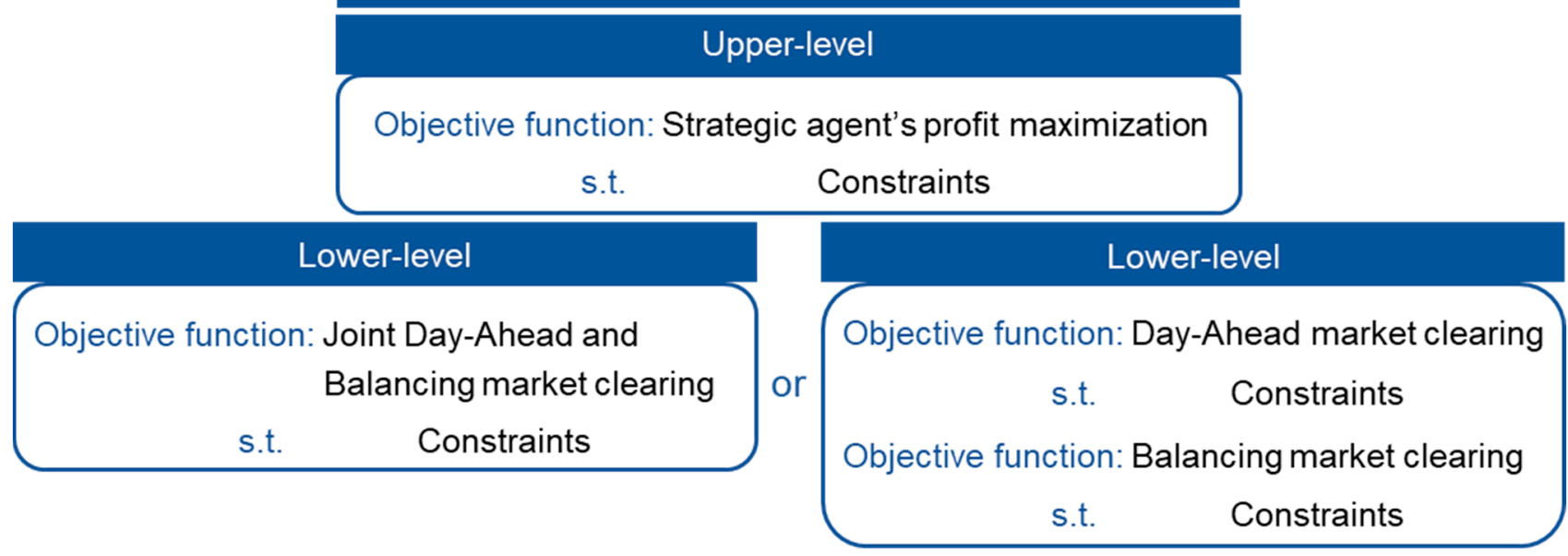

Figure 2. Bi-level framework of strategic agent's behavior.

In order to efficiently generate solutions though, bi-level model is recast into a mathematical program with equilibrium constraints (MPEC). MPECs are complementarity hierarchical problems, that are extensively used in modelling a broad range of marketbased scopes. Investment and sizing models for market agents, as well as the demand-side strategic bidding, are well-established examples of the MPECs' applicability. However, in the context of this specific review, solely the efficiency of MPECs in modelling the optimal offering strategies of energy generators when participating in deregulated electricity markets, is examined.

The MPEC models' structure consists of the upper-level's objective function and the Karush-Kuhn-Tucker (KKT) optimality conditions of the lower level one, as depicted in Figure 3. Naturally, the convexity of the lower-level problem is a prerequisite, in order for this to happen.

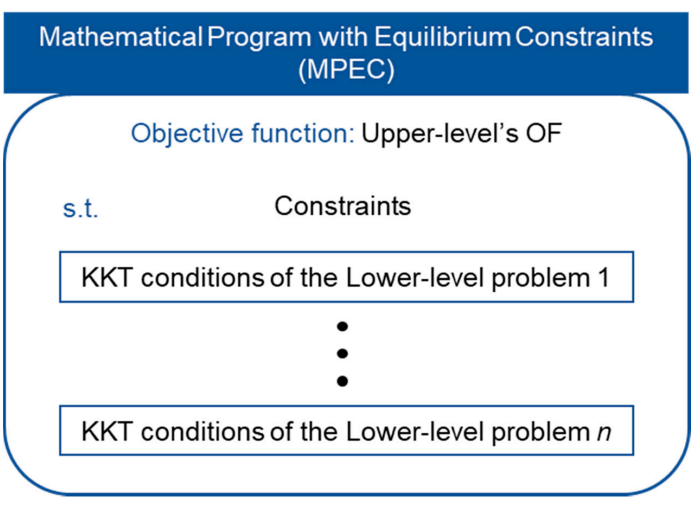

Figure 3. MPEC formulation. 
Karush-Kuhn-Tucker conditions are characterized as first-order conditions, as they are formulated through first derivative vectors and Jacobian matrices, and their implementation constitutes an essential requirement for the solution of various non-linear bi-level optimization problems.

The formation of the Lagrangian function:

$$
\mathcal{L}=f(x)+\lambda^{T} h(x)+\mu^{T} g(x)
$$

facilitates the representation of the KKT conditions, with $f(x), h(x)$ and $g(x)$ being continuously differential in the resulting feasible region.

$f(x)$ represents the objective function of the upper-level problem, while $h(x)$ and $g(x)$ represent equality and inequality constraints equivalently.

The KKT optimality conditions are:

$$
\begin{aligned}
& \nabla_{x} f(x)+\lambda^{T} \nabla_{x} h(x)+\mu^{T} \nabla_{x} g(x)=0 \\
& h(x)=0 \\
& \mu^{T} g(x)=0 \\
& \left.\begin{array}{l}
g(x) \leq 0 \\
\mu \geq 0
\end{array}\right\} 0 \leq \mu \perp g(x) \leq 0
\end{aligned}
$$

where Equation (2) incorporates complementarity conditions and $\lambda, \mu$ denote the equality and inequality Lagrange multiplier vectors, respectively.

\subsection{Imperfect Competition-Market Equilibria}

Nash equilibrium is a game-theoretic decision-making concept dictating that a game's optimal outcome, is when there is no incentive for a player to deviate from its initially chosen strategy, after examining its opponents' decisions. Each game may have a plethora of Nash equilibria or none. Nevertheless, it is important to emphasize that Nash equilibrium does not automatically ensure that optimal strategy is always embraced.

Several modelling approaches have been employed for the actual representation of generating companies' behavior under oligopolistic market frameworks, with the main ones being conjectural variations (CV) and equilibrium problems with equilibrium constraints (EPECs).

In the conjectural variation models, which constitute a generalization of the classic Cournot approach, a firm can make assumptions about other firms' output variations in order to incorporate them into its own decision-making process. An excellent review proposed by Diaz et al. [33] evaluates all the different types of conjectural equilibrium models used in electricity markets, classifying them according to whether the conjectures are handled, as exogenous or endogenous variables.

On the contrary, the joint consideration of all individual MPECs, each one modelling the strategic behavior of a generating agent seeking to exert market power in electricity markets, constitutes an EPEC, as depicted in Figure 4. In this type of Stackelberg hypothesis games of asymmetric information, leaders attempt to correctly anticipate follower's reaction, which in this case is the national market operator that acts as if has no influence on the leaders' output, while a Nash equilibrium is pursued among the multiple generators-leaders.

Equilibrium Problem with Equilibrium Constraints (EPEC)

MPEC 1

MPEC $n$

Figure 4. EPEC formulation. 
The work by Devine et al. [34] demonstrated that the CV approach can lead to myopic and contradictory results in oligopolistic electricity markets, and that an EPEC model can overcome these difficulties and more realistically represent firms' behavior in such a market structure.

\subsection{Solution Approach}

Since current NLP solvers cannot efficiently tackle large-scale non-linear algorithms, the development and implementation of coherent solution methodologies for MPEC models, constitute a challenging priority. A number of alternative techniques, including the penalization of complementarity constraints in the objective function, or Sequential Quadratic Programming (SQP) [35] have been proposed for this purpose, with the Fortuny-Amat and McCarl linearization approach [36] being the most popular option. The binary expansion method [37] proposed by Pereira et al. constitutes an additional great technique to eradicate nonlinearities and substitute them, with a set of multiple parameters. However, this technique adds significant computational costs due to the extra variables required, making it impossible to be applied in large-scale problems. On the contrary, decomposition algorithms, such as the iterative Benders procedure [38], allow the solution of complex and computationally demanding problems in a distributed manner.

The solution of an EPEC is still considered a challenging problem in optimization and game theory societies, due to its non-convex and non-linear nature, and is attained by jointly solving a number of interrelated MPECs. The most familiarized strategy for solving an EPEC in the recent literature is the application of the iterative diagonalization procedure, which dictates the solution of each player's MPEC sequentially until convergence is achieved and is thoroughly presented in [39]. As pointed out by Pozo et al. [40], yet to date a global optimum solution in EPECs is rarely reached; instead, stationary alternatives, such as saddle points or Nash and local equilibria are usually obtained.

\section{Key Research Contributions}

\subsection{Perfect Competition and Single Leader-Single Follower Games}

\subsubsection{Electricity Market}

The electricity market clearing and the determination of the optimal offering strategies for participating agents are considered areas of particular interest in the scientific community and several excellent reviews have been published on this topic. However, to the best of our knowledge, no reviews have been proposed to include the latest research contributions and this is the aim of this work.

Ruiz and Conejo [41] are some of the first to propose a non-linear bi-level optimization mathematical framework to derive the optimal strategic decisions of a power generator, participating in a pool-based electricity market and a network-constrained six-bus test system. Their work is considered a key milestone on which, the vast majority of subsequent relevant articles were based. The upper-level objective aims at maximizing the strategic producer's profit, while the lower-level problem represents the market clearing procedure, deriving the local marginal prices (LMPs) endogenously, with respect to social welfare maximization. The algorithm is reduced to a mixed-integer linear programming (MILP) problem using well-established mathematical techniques such as the strong duality theorem, Karush-Kuhn-Tucker optimality conditions and Fortuny-Amat and McCarl linearization approach. The computational analysis demonstrated the capability of the proposed model to generate optimal multiple-block offers for the strategic producer and the fact that network congestion can be highlighted as a profit-increasing factor.

Gabriel and Leuthold [42] presented a novel linear bi-level model to capture the behavior of a strategic player, acting as a Stackelberg leader and exercising market power in a network-constrained electricity market, where ISO acts as a follower, considering offering decisions of competitive firms. Large-scale electricity generation companies, such as EDF, Electrabel, EON and RWE are considered as Stackelberg leaders. A thorough comparison between perfect and imperfect competition market setups is conducted, and the effects 
of network congestion are analyzed. Results indicate that the proposed mathematical approach is promising in addressing realistic problems and that when these firms act strategically (particularly EDF), they acquire a great profit increase.

Although binary variables constitute fundamental elements to model non-convexities, such as electricity generators' minimum power outputs and start-up costs, they prevent MILP models to obtain market clearing prices as dual variables of the energy balance equations. Ruiz et al. [43] addressed this problematic situation by proposing a novel primaldual multi-block formation that ensures well approximated social welfare compared to the original clearing problem. The suggested approach provides LMPs for a single-shot pool-based market and guarantees generators' revenue adequacy, without incorporating additional uplift charges. Simulation analysis illustrates that both market prices and total profits are higher in the relaxed duality approach when compared to the equivalent conventional one. Ruiz et al. [44] extended their research scope considering a strategic electricity producer participating in an electricity market regime, similar to the ISO New England and PJM, interested in revealing its rival producers' offering decisions, via inverse optimization. The market-clearing procedure conducted by the Independent System Operator (ISO) is expressed by a primal linear optimization problem formulation, aiming at social welfare maximization and its equivalent dual formulation. The solution of these problems provides the main market outcomes, such as power produced by block for each generator and local marginal prices for each electric network bus. Consequently, considering these outcomes, the inverse problem is developed and solved by the strategic producer, in order to identify rival stepwise offer prices setting the market-clearing price. Results indicate that network congestion stimulates the offer price revealing process on account of the strategic generator.

Kardakos et al. [45] introduced a bi-level mathematical model to derive optimal offering strategies for a strategic producer, owning multiple generating units, under a day-ahead transmission-constrained electricity market setup. The upper-level represents the producer's detailed unit commitment problem aiming at maximizing its expected profit, whereas the lower-level illustrates ISO's hourly market clearing mechanism, under the Nodal and the Power Transfer Distribution Factor (PTDF) formulation. The particular methodology is implemented on a modified IEEE 118-bus power test system, to examine its applicability and efficiency, in a realistic pool-based market environment. The authors [46] extended their research forming a stochastic bi-level mathematical model, considering a price-maker virtual power plant (VPP), which consists of wind farms, battery storage systems and residential/commercial electricity consumers. Uncertainty is introduced into the problem, via unpredictable market measures, such as RESs' generation, demands' consumption, rivals' offering curves and real-time prices. A series of case studies applied to the Greek power system are examined. Numerical results demonstrate that the coordinated operation of VPP elements leads to a significant profit increase by $4.7 \%$, compared to the uncoordinated operation scenario. Furthermore, it is illustrated that when VPP acts as a price-maker agent, acquires higher profits in comparison to the price-taker or nonstrategic case.

Several European electricity markets nowadays, such as Germany and Italy, have adopted a pay-as-bid pricing scheme in the balancing stage. While these markets' trading problem is typically addressed through non-linear optimization approaches, Mazzi et al. [47] proposed a leading-edge linear formulation to bypass possible computational challenges, instigated by these nonlinearities. More specifically, authors considered a two-stage stochastic MILP model to derive optimal offering strategies for a price-taker conventional generator, under a simultaneous clearing of a two-settlement electricity market, i.e., the day-ahead stage, characterized by a uniform pricing scheme, and the balancing stage, based on a pay-as-bid pricing scheme. Results underline the efficiency of the linear formulation, as it fairly approximates the non-linear one, and demonstrate that the simultaneous market clearing, provides better performance in view of the generator's profitability, compared to 
the sequential market-clearing case. However, the application of the model to a multi-bus electric network could provide better insights into its efficiency in large-scale problems.

Lastly, Porras-Ortiz et al. [48] introduced an inspired bi-level mathematical approach, for a strategic zonal operator in a regional electricity market (REM) setup. In the upper-level optimization problem, the strategic operator seeks to maximize zonal social welfare (ZSW), by managing zonal generators' strategic day-ahead energy and reserve offers, whereas the objective function of the lower-level problem aims at maximizing regional social welfare and generating market equilibrium prices and dispatches. Results emphasized that strategic behavior on behalf of the zonal operator can negatively affect regional social welfare and induce crucial alterations in congestion rents.

\section{Integration of Wind Power Producers}

As already mentioned, the production of electricity from renewable sources constitutes a crucial step in reducing the environmental footprint of the modern world and has a direct impact on the tariff regime and structure of competitive electricity markets. Among the various types of RES, the participation of wind farms in contemporary market settlements seems to be of the greatest scientific interest, mostly due to their operational and financial advantages, compared to the rest of the intermittent technologies.

Morales et al. [49] were among the firsts to propose a mathematical framework that delves into wind power generators' actions. They formulated a multi-stage stochastic LP problem to generate optimal offering strategies and maximize expected profits for a wind power generator, in a joint day-ahead, adjustment and balancing market settlement. Uncertainty induced by wind availability and hourly market clearing prices at different trading stages is modelled through the realization of weighted plausible scenarios, the higher quality of which leads to more reliable and representative results. Consequently, the authors [50] developed a fundamental two-stage stochastic electricity pool-based marketclearing approach, including a substantial number of wind power generators (WPG). The first stage represents the day-ahead market clearing procedure, while the second stage presents the balancing system operation, under a set of plausible wind generation realizations. Co-optimization of both electricity and reserves, endogenously provides pool (day-ahead) and real-time energy prices, as dual variables of the equivalent energy equilibriums. The proposed algorithm is studied in a 24-bus transmission-constrained single-area IEEE RTS [51] and ensures producers' cost recovery and revenue reconciliation in expectation.

Baringo et al. [52] formulated an inspired stochastic bi-level mathematical model, to derive optimal offering strategies for a wind power generator, exercising its market power by participating as price-maker in the day-ahead stage, while acting as a deviator in the real-time stage. A set of weighted scenarios is employed to imprint the uncertainty induced by wind production and real-time market price. The upper-level problem, seek to maximize the wind producer's expected profit, whereas the lower-level objective function represents the day-ahead market clearing process, in terms of maximizing social welfare. Case studies performed, indicate a sound escalation of wind producers' expected profits and market prices, when adopting strategic behavior, compared to the non-strategic state, and a parallel decrease in social welfare. The considerable size of test systems (up to 118-buses), combined with their negligible temporal computational requirements, highlight the applicability of the proposed model in real-world power networks.

Zugno et al. [53] investigated the optimal offering strategies of a wind power generator by acting as a price-taker in the day-ahead market and as a price-maker in the balancing market. The uncertainty inserted in the system concerns the day-ahead market price, wind generation and residual system deviation and is modelled through the weighted probabilistic realization of different scenarios. The case study considered the Scandinavian electricity market framework and one price balancing market settlement, with one of the critical findings of this work reporting that the optimal offer for the wind producer in the day-ahead market increases analogously to its market penetration. Pandžić et al. [54] 
considered a virtual power plant (VPP) with a mixed generation portfolio (conventional (CPP), wind (WPP) and pumped hydro storage (PHSP) power plants), purchasing and selling electricity in a joint day-ahead and real-time market setup. A two-stage stochastic MILP framework is designed, in order to maximize VPP's expected profits, which acts as a price-taker in the day-ahead market and as a passive agent in the balancing market. Numerical analysis illustrates that the majority of energy is traded on the day-ahead floor, while the balancing market revenue constitutes less than $2 \%$ of the overall earnings.

Delikaraoglou et al. [55] introduced a bi-level mathematical configuration based on the Stackelberg hypothesis game, where wind power generator acts as a leader (price-maker) in both day-ahead and balancing market, while system operator, as a follower. The stochastic nature of the power production of non-dispatchable agents is inserted into the problem via 50 different plausible wind generation scenarios using a Beta distribution. A case study applied in an IEEE RTS, showed that the strategic wind producer improves its expected profits by regulating its day-ahead quantity offers and avoiding severe upregulation costs.

Dai and Qiao [56] proposed a bi-level stochastic mathematical model to derive the optimal offering strategy for a wind power generator acting strategically in a pool-based electricity market. The upper-level problem maximizes the total profit of the strategic producer, while at the lower-level one, a sequential clearing procedure of the day-ahead and balancing market takes place. The risk induced by the uncertainty in demand power consumption, wind power production and offering strategies of power producers is managed by including the conditional value at risk of the worst-case scenarios in the objective function. The above methodology is applied to the IEEE RTS and features significant results such as: the day-ahead and balancing LMPs decrease as the market share of wind power generation amplifies, the network congestion can be exploited by the wind power producer to further arbitrage and increase its expected profits. Reddy et al. [57] recommended novel electricity and spinning reserves market clearing mechanism for a power system, comprised of conventional and wind generators, under wind power generation uncertainty. More specifically, the authors calculated a real-time adjustment cost, deploying data from the day-ahead schedule and plausible balancing operating scenarios, and incorporated it in the day-ahead problem, to address the uncertainties that emerged. The mathematical approach consists of two discrete models, with the first one accounting for spinning reserve deployment exclusively by thermal generators, whereas the second one also allows the participation of demand-side offers in reserve market setup. The proposed technique is tested on an IEEE 30-bus system, while the results' validation is realized through the Monte Carlo Simulation method.

Exizidis et al. [58] proposed a stochastic bi-level mathematical model to analyze the impact of rival wind generators, on the optimal bidding strategy of a WPP, exercising market power in a deregulated electricity market settlement. Power generation of both strategic and non-strategic WPPs is considered as the problem's uncertainty source and is modelled through a set of foreseen balancing scenarios. The algorithm is applied to an IEEE one-area RTS, while numerical analysis reveals that strategic WPP further exerts market power, when having a mid- or low-mean forecast distribution and that its bidding strategies firmly depend on rival wind power production. Soares et al. [59] developed an optimization framework to derive optimal bidding strategies for a wind power producer, participating in an electricity and primary reserve market setup. Authors considered two different reserve offering strategies, i.e., proportional and constant, the discretization of which lies on the allocation of wind power generation in energy and reserve markets. Despite their divergent characteristics, quantitative analysis shows that both approaches ensure critical profit increase for the wind plant owner, especially in comparison to an energy-only bid case and are firmly affected by market prices and penalties from being insufficient to meet market requirements. Finally, a central conclusion of this work states that, even though the provision of market services by a wind power plant is technically feasible, it is not a common tactic in current market environments. 
Tsimopoulos and Georgiadis [60] presented a bi-level optimization model to derive optimal hourly offering strategies for a conventional power producer possessing a dominant position in the pool-based electricity market, under high penetration of non-dispatchable generation. The case study pertains to a network-constrained 2-bus system, while network congestions' outcomes are also investigated, as capacity decrement of the transmission line constitutes a possible contingency. Additionally, a thorough comparison is carried out regarding the market price scheme and the electricity dispatch, when the conventional generator under study, acts strategically versus as a price-taker.

Tsimopoulos and Georgiadis [61] extended their work to incorporate the stepwise offering strategy for the dispatched energy production and consumption blocks, introduced by Ruiz and Conejo (2009). This offering structure requires, accepted energy blocks to be offered at their marginal cost, whereas marginal blocks at the equivalent market price, to avoid multiple solutions and degeneracy. Results reinforced findings from previous contributions on this topic and showed that expected profits of strategic agents decrease, while wind generation's market share increases. Tsimopoulos and Georgiadis also [62] examined the optimal withholding strategies for an agent with a mixed conventional and wind production portfolio, participating in a pool-based electricity and reserve market. The upper-level of the proposed mathematical framework guarantees profit maximization for the market agent under study, whereas at the lower level the simultaneous day-ahead and balancing market clearing process is modelled, through a two-stage stochastic programming. Aftermath established the general perception that the strategic agent can financially benefit from network congestions, by charging the production blend and exploiting transmission line capacities.

Finally, Rintamäki et al. [63] recently proposed a bi-level optimization model to study the optimal offering decisions of a flexible generator in day-ahead and intraday markets. The upper-level problem's objective concerns the profit maximization of the generator, while the lower-level one represents the sequentially market-clearing procedure of the markets. At first, the authors considered a three-node transmission constrained network and demonstrated that the flexible generator can increase its expected profits by regulating its offers, in order to cause transmission congestion or shortage on price-takers generators' capacity. Furthermore, the authors applied their optimization model in a Nordic 5-node test network and confirmed this flexible benefit to a greater extent when acting strategically under imperfect forecasts, compared to a perfect competition setup. However, the application of this model to a larger scale problem is necessary in order to obtain reliable results regarding its effectiveness.

\section{Integration of Electricity Storage Agents}

Given the strong penetration and the growing market share of renewable energy sources, as well as their stochastic nature regarding electricity generation, the role of electricity storage in mitigating potential market imbalances becomes particularly important. For this reason, a plethora of research publications has emerged in recent years to evaluate the strategic and non-strategic market behavior of various storage technologies.

Kazempour et al. [64] introduced a mixed-integer non-linear mathematical approach to address the shelf-scheduling problem of a hydro generating company, consisting of several hydro plants and a pumped storage facility. The optimization framework aims at maximizing the company's profitability, which acts as a price-taker when participating in day-ahead energy, spinning reserve and regulation markets. Kanakasabapathy et al. [65] formulated a multistage looping algorithm to examine the optimal offering/bidding strategy for a hydro-pumped storage plant in a pool-based competitive market regime. The proposed mathematical framework, taking into consideration technical characteristics of the plant, managed to maximize its expected profit in day-ahead and ancillary services market by finding optimal operation schedules, i.e., operating at discharging mode when market-clearing price ranges at high levels and at charging mode when electricity market price is low. 
A truly inspiring work by Drury et al. [66] laid the foundations for the modelling of CAESs' integration in electricity markets. In particular, they formulated a mixed-integer linear program to derive the optimal offering/bidding strategies for a conventional and an adiabatic CAES in several day-ahead electricity and reserves U.S. markets, such as CAISO, MISO, PJM and NYISO. Numerical analysis validated, that conventional CAES facilities can financially capitalize on the provision of multiple grid operating services, in addition to their scheduled energy dispatch, so that the investment becomes economically viable. On the contrary, the revenues of adiabatic CAES could not support the investment's realization, in any of the above-market settlements. Furthermore, design parameters of a CAES device, such as expander and compressor size, round-trip efficiency and stored energy capacity, seemed to affect arbitrage revenues, but not the reserve and capacity-based income streams.

Akhavan-Hejazi and Mohsenian-Rad [67] developed a stochastic programming optimization framework to acquire optimal day-ahead and balancing energy and reserve offers/bids, for a group of investor-owned electricity storage units, under high wind power penetration. The results showed that design parameters such as size and location, as well as market-clearing price forecasts, can hold a critical impact on decision-making and profit maximization of the electricity storage units and compensate for the uncertainty, induced by wind power generation fluctuations. A year later, the same authors [68] provided an optimization mathematical framework to derive optimal offering/bidding strategy of a battery storage agent, to maximize expected profits from its participation in a jointly operated multi-temporal day-ahead and balancing market-clearing procedure. Authors, adapting Markowitz portfolio theory and using a receding horizon algorithm in balancing market, update expected revenues and financial value at risk forecasts, to attain the optimal agent's operation. Results emphasized the dominance of risk-constrained market optimization over the corresponding risk-free, concerning agent's profit gaining and established risk of stochastic revenues as a critical factor, on whether the ESS will deploy or renounce balancing market revenues.

Awad et al. [69] presented a novel mixed complementarity model to determine the optimal dis(charging) strategy of an Energy Storage System (ESS) in a single auction perfectly competitive electricity market structure. The mathematical framework aims at satisfying hierarchically three different objectives such as social welfare maximization, hourly electricity price minimization and ESS's arbitrage profit maximization. The model was applied to a 6-bus transmission constrained network and a 3-bus distribution system interconnected through a transformer. The results show that the ESS's operation positively contributes to the compression of the highest market-clearing price during off-peak time intervals, whereas its size and location have a critical impact on market prices and arbitrage efficiency. Pandžić and Kuzle [70] formulated a bi-level optimization model to assess the optimal operation and offering strategy of an investor-owned battery energy storage (BES) system in the electricity market. The upper-level describes the profit-maximization problem of the strategic agent, while the lower-level problem simulates the day-ahead market clearing procedure with respect to social welfare maximization. Solution algorithm outcomes report that location, size and submitted offers of BES should be determined in a way that will not significantly affect local marginal prices, otherwise, energy storage agents may incur profit losses. Additional results state that a prominent penetration of wind generation in the power system, as well as occasional network congestions, can empower BES's arbitrage potential, verifying equivalent theses designated by previous works.

Ding et al. [71] introduced an insightful stochastic optimization formulation to derive optimal day-ahead offering and balancing operation strategies for a WF-ESS (wind farmenergy storage system) integrated producer, acting as a price-taker in a two-price market settlement. The cooperation of these entities lies on the concept that ESS can assimilate and compensate for plausible generation imbalances from the WF, by arbitraging and setting well-designed (dis)charging reserve capacities. The proposed nonlinear nonconvex model is solved through the application of a modified gradient descent algorithm, whereas 
wind power uncertainty is modelled by adopting a probabilistic distribution, contrary to the generic methodology accounting for plausible wind generation scenarios' realization. Results indicated that the recommended modified algorithm accomplished superior convergence and optimality as opposed to the conventional one, whilst the proposed offering and operation strategy ensured higher profit earnings when compared to three widely employed in literature strategies.

Mohsenian-Rad [72] developed an optimization-based mathematical framework considering a large price-maker group of independently operated BESs, who aim at coordinating their (dis)charge operation scheduling, in order to maximize their expected profit. Furthermore, the author addresses the impact of critical energy storage design factors such as size, location, (dis)charging efficiency and rates on the configuration of the local marginal electricity prices. The results arisen, emphasized the common state, that transmission line congestions can prove beneficial for the price-maker profit increase, while the presence of ESSs appeared to contribute to the reduction in overall power system generation cost. Moreover, locational dispersion of units in multiple nodes seemed to attract higher earnings for a storage firm, instead of installing the majority of the units in a single network location. Finally, while self-scheduling and economic bidding are not characterized by great differences in a deterministic design scenario, the latter bidding type guaranteed higher profits, under a stochastic optimization approach.

Nasrolahpour et al. [73] proposed a bi-level optimization framework to model the optimal planning and operation strategies for an energy storage agent participating in a deregulated electricity market setup. The proposed mathematical methodology based on Bender's decomposition algorithm, due to the problem's computational complexity, was applied to Alberta energy-only market, considering real-life data, a hydro-pump storage facility as the strategic agent and an imperfect competition market setup. Results affirmed that the problem parameters' determination must be approached meticulously, as storage agents' decisions are highly influenced by the established assumptions and scenarios. Nasrolahpour et al. [74] also investigated the optimal offering/bidding strategies of an electricity storage facility in perfectly and imperfectly competitive electricity market settlements. A bi-level optimization model was developed, to investigate the interactions between the energy storage merchant and system operator in a six-bus power network, during a 24-h planning horizon. Results demonstrated that the expected profits of the energy storage facility in an imperfect competition market setup, is almost $60 \%$ higher than the perfect competition case.

Nasrolahpour et al. [75] extended their research scope by formulating a bi-level mathematical configuration, to generate the optimal offering/bidding strategies for a price-maker ESS, participating in energy and reserve markets. The objective of the upperlevel problem accounts for the profit-maximization of strategic ESS agents, whereas the lower-level problems, pertaining to the sequential clearing of a joint energy and reserve day-ahead market and balancing market. Authors initially applied their optimization algorithm in a single-bus illustrative test system, to investigate ESS's profit fluctuations, under energy-only versus joint energy and reserve market setups. Results highlighted the superiority of the energy and reserve day-ahead and balancing market setting, apropos of ESS's profitability. Consequently, the optimal strategies for a large-scale CAES facility participating in Alberta Electricity Market were also determined.

Ye et al. [76] introduced a bi-level mathematical model to provide a theoretical and quantitative evaluation of the positive contribution of energy storage facilities in mitigating dispatchable generators' market power, in imperfectly competitive electricity markets. Profit maximization of strategic generation companies is the objective of the upper-level problem, while the lower-level one represents the day-ahead electricity market clearing with the hourly resolution, taking into consideration the intertemporal operation of the storage agent. Results show a critical impact of electricity storage on moderating strategic generators' market power. More specifically, as energy storage's deployment in the market increases, peak/off-peak generation-demand asymmetries flatten, thus decreasing genera- 
tors' expected daily profits and consolidating consumers' financial surplus. He et al. [77] formulated an optimization framework including the PJM's performance-based regulation (PBR) mechanism, to derive the optimal offering/bidding strategy of a price-taker battery energy storage (BES) system participating in joint energy, spinning reserve and regulation day-ahead market setting, under price uncertainty. Furthermore, a battery cycle life mathematical configuration and a decomposition algorithm are incorporated into the existing optimization scheme, to analyze the battery cycle's life impact on the BES's optimal operation decisions and generated profits. Numerical results state that both battery cycle life and PBR mechanism critically enhance BES's day-ahead bidding strategy and economics, while the applied decomposition approach substantially reduced the problem's modelling and computational requirements.

Contreras-Ocaña et al. [78] developed a bi-level mathematical frame to study the ESS's strategic bidding effects on rival market participants. The upper-level problem aims at maximizing strategic ESS's expected profits, whereas the lower-level one presents, the market-clearing process conducted by ISO, endogenously generating pool prices, with respect to social welfare maximization. Simulations performed in an IEEE RTS, highlighted that despite the fact that ESS's strategic bidding can negatively affect social welfare, its market participation is preferable to an utter electricity storage shortage hypothesis. Ding et al. [79] proposed a stochastic mixed-integer linear mathematical model to derive the optimal bidding and operating strategies of a large-scale wind farm-energy storage system (WF-ESS), acting as a price-maker in the day-ahead market and in parallel adopting linear decision rules in real-time markets. The case study, where the above optimization framework was applied, accounts for a hydro-pumped storage plant and real-life data for wind farms located in Denmark, whereas the market settlement simulates a modified one-price balancing Nord Pool market. Numerical results emphasized that WF-ESS agent can attain more than $60 \%$ of its overall profits in the balancing market when acting as a price-maker in the day-ahead market.

Vespermann et al. [80] considered a bi-level optimization framework to investigate the optimal offering/bidding strategies of an ESS agent in electricity markets, under stochastic wind power generation. Authors analyzed ESS's outcomes, under three discrete scenarios apropos of its offering strategy, i.e., (i) when ESS acts as a price-taker in both day-ahead and balancing markets (NS), (ii) when storage operator acts as a price-maker in the balancing market and as a price-taker in the day-ahead market (S-BA) and (iii) when ESS acts strategically by maximizing its profits in both trading floors (S-DABA). Numerical results from the implementation of the proposed mathematical methodologies in an IEEE 24-bus RTS, underlined the superiority of the S-DABA offering strategy over the alternative ones, in terms of ESS operator's expected profit maximization.

Wang et al. [81] presented a novel hybrid look-ahead bi-level approach to determine the optimal profit-maximizing offering/bidding strategies of a merchant storage agent, for the day-ahead and the following day market. The overall analysis is considered as particularly important, as ESS capitalizes the fact that its state-of-charge (SOC) at the end of the opening trading day, coincides with the initial SOC for the succeeding trading day, thus optimally positioning itself to exploit every possible arbitrage opportunity in the following day market window. Furthermore, to account for potential future risks and incorporate forecast uncertainty, a conditional value-at-risk analysis is implemented. Numerical simulations illustrated that several design and market factors, such as the look-ahead window duration, the storage operator's costs, the ramp rate of dispatchable producers, as well as the forecast uncertainty, can significantly affect the optimization outcomes. Wang et al. [82] expanded their previous work, by analyzing the impact of network transmission congestion on energy storage's optimal decisions and arbitrage opportunities, under perfect and imperfect competition in a modified 24-bus IEEE RTS. Results indicated the beneficial contribution of transmission congestions and the significance of location determination, on energy storage agents' expected profits, under both market setups. Moreover, while local marginal prices in perfect and imperfect competition do not differ substantially, strategic 
bidding instigates considerably higher profitability for the ESS operator, especially under severe local congestion conditions.

Ye et al. [83] formulated a bi-level optimization approach to model the decisionmaking mechanism of a strategic ESS operator participating in the day-ahead pool-based market with hourly resolution. Quantitative analysis showed, that both higher power rating and increased energy capacity, enhance strategic ESS's profit escalation and potential in affecting market prices, up to a certain level from which and after saturation effect takes place. Nojavan et al. [84] proposed a robust mixed-integer linear programming (RMIP) methodology to achieve the optimal profit-maximization offering/bidding strategies for a compressed air energy storage (CAES) system, participating in a pool-based day-ahead electricity market. The authors analyzed three different cases depending on the market price value, i.e., optimistic, deterministic and pessimistic. Results showed that total CAES's profits in the optimistic case increased up to $30.3 \%$, while in the pessimistic case decreased by $54.28 \%$, in comparison with the deterministic one. The RMIP approach was considered particularly efficient, as it guaranteed superior uncertainty handling and less computational effort, in comparison with stochastic optimization techniques. Schillemans et al. [85] proposed a bi-level optimization technique to derive optimal offering/bidding strategies for a merchant ESS, participating in joint energy, reserves and balancing markets. In the upper-level problem, the ESS agent aims at maximizing its expected earnings, whereas the lower-level problem represents a jointly cleared day-ahead energy/reserve and balancing market settlement. The uncertainty induced by real-time imbalances is epitomized by a probability density function and is embodied into the model through the realization of probabilistic reserve constraints, presented in [86].

Tómasson et al. [87] presented an inspired optimization framework to analyze the optimal offering/bidding strategies of a merchant electricity storage system in order to maximize its expected profits under several plausible market scenarios. The initial nonlinear stochastic bi-level problem is reformulated into a stochastic disjunctive program, which is then solved through a specialized branch-and-bound (SBB) algorithm, thus reducing the problem's computational requirements and avoiding the conventional Big-M linearization technique for lower-level problem's complementarity slackness conditions. A series of numerical simulations carried out revealed several alternatives for the strategic storage agent to exercise market power and affect clearing prices, such as demand and capacity withholding and under-used storage.

Khatami et al. [88] proposed a look-ahead technique to account for the optimal profitmaximizing operation decisions for a compressed air energy storage (CAES), in day-ahead and balancing energy and ancillary services markets. The mathematical configuration composed as a MILP problem uses real-life price data from CAISO and achieves additional profits for CAES, as it co-optimizes the capacity of the compressor and expander, over a future scheduling horizon. Results showed that the suggested approach ensured higher profitability for the energy storage facility, in comparison with a short planning horizon case. Lately, Khaloie et al. [89] formulated a stochastic multi-objective optimization algorithm, to generate optimal offering strategies for a wind-thermal-electricity storage (WTES) system, in a coordinated energy and spinning reserve market setup. The primary objective function (OF) represents the system's profit maximization during a day-ahead scheduling horizon, whereas the secondary OF aims at minimizing the agent's expected emission, which emerged from thermal units' deployment. To effectively solve the above bi-objective mathematical framework, the authors applied a modified epsilon constraint technique to provide the trade-offs between OFs and obtain a Pareto optimal solution. The numerical analysis highlighted the superior profitability of WTES company when the storage system participates exclusively in the spinning reserves market.

\subsubsection{Coupling of Electricity and Natural Gas Markets}

The coupled operation of electricity and natural gas markets is considered to provide significant benefits as it allows better coordination and information exchange between the 
two systems and also reduces the overall cost. In recent years, there seems to be a particular shift towards this operation, with more and more organizations worldwide choosing to adopt it.

Duenas et al. [13] were some of the first to study the market coupling and develop a mixed integer programming problem to simulate the optimal long- and medium-term operation of a power generation company (Genco), owning a group of gas-fired power plants (GFPPs), under a coordinated competitive electricity and gas market settlement. The model also accounts for the simultaneous optimization of natural gas purchases in a zonal gas spot market and minimization of long-term natural gas pipeline capacity contracting costs under renewable energy sources (RES) power generation uncertainty.

As interactions between electricity and natural gas markets are increasing, a plethora of companies appears to act simultaneously as major players in both markets, by operating a decision-making department for each market. Gil et al. [90] developed two mathematical approaches to simulate each's departments optimization actions. The "electricityperspective" approach accounts for the maximization of the electricity market profit, after generating equivalent natural gas contracts via the implementation of the gas market algorithm. On the other hand, the "gas-perspective" method aims at minimizing natural gas operation costs, in the aftermath of acquiring the correlation between marginal revenue and gas consumption by the electricity market equilibrium problem. Results display, that both methodologies produce identical optimal solutions and are characterized by sufficient adaptability.

Ordoudis et al. [91] proposed an insightful price-based (PB) stochastic bi-level approach, considering a coupled electricity and natural gas market, where gas consumption and price offered by NGFPPs, constitute the coordination parameters between the two market setups. The recommended optimization mechanism ensures that ISO will form a financial day-ahead equilibrium, whereas may encounter an implicit real-time shortage or surplus. Numerical analysis reveals a substantial market efficiency increase, due to a significant reduction in the overall system cost, through an enhanced unit dispatch, that successfully addresses stochastic generation. The authors extended their research approach to examine the coordination of electricity and natural gas markets, in view of their mutual interactions and time intersection of day-ahead/real-time trading floors [16]. More specifically, three mixed-integer linear programming (MILP) approaches are presented accounting for the linepack of the natural gas network, i.e., a coupled and a decoupled deterministic sequential and a coupled stochastic market clearing procedure. Results demonstrated that although all three models adequately capture gas system operation, coupled stochastic scheme ensures the lowest expected costs and incorporates uncertainty induced by significant amounts of wind energy in a preferable manner, compared to the remaining two methodologies.

Ordoudis et al. [92] depending on their previously developed PB method, established a novel volume-based (VB) coordination approach, to reduce the expected cost of an integrated electricity and natural gas system, by optimally defining gas availability for power generation by GFPPs, under high shares of renewable energy. The presented bi-level mathematical formulation seeks to improve day-ahead and real-time stage coordination while conforming to the sequential market-clearing settlement, which constitutes the current market design. Nevertheless, as clearly emphasized by the authors, the presented algorithm cannot be adopted as a realistic market-clearing model. A realistic analysis is conducted to evaluate the proposed model's performance and compare it with the PB method; thus, an identical integrated power and gas system setup is employed. Results revealed that an efficient adjustment of natural gas quantities or prices can critically enhance the performance of the sequential market-clearing model, in terms of minimizing system cost, so as to resemble the ideal condition of stochastic modelling.

Chen, Wang and Sun [93] recommended a non-deterministic scenario-based mathematical model for the day-ahead market clearing, under a coordinated electricity and natural gas market setup. This approach achieves a direct link between the flexible resources and 
the system uncertainties arising from RESs' (wind and solar) unpredictable power production, thus enhancing economic efficiency. Case studies indicate a more suitable allocation of available resources, such as gas transmission capacity, as joint market curtails (with the analogous compensation) low-priority gas demand loads, in order to meet electricity demand and ensure the power system's stability. Solution time ranges at reasonable levels, considering the substantial size and complexity of the proposed algorithm. However, the general assumptions and compromises made to reduce computational requirements, render the proposed model inadequate to be implemented in current market designs.

Zhao et al. [94] developed two independent optimization frameworks for the dayahead market-clearing of power and natural gas systems. The coordination between these two systems is implemented via an iterative heuristic algorithm, which is based on Lagrangian Relaxation, which allows the exchange of fundamental information such as fuel price, supply and demand and aims at maximizing social welfare. The purpose of such coordination lies in ensuring that, natural gas supplied to the power system to meet electricity demands, does not result in gas loads' curtailment. Results revealed that gas curtailments may lead to unserved energy in the electricity system, which can cause a great social welfare reduction and a parallel electricity price increase. Yan et al. [95] considered an Integrated Energy System (IES) with multi-type energy units and storage systems, integrated into a coupled simultaneous day-ahead electricity and natural gas market, including carbon emission market. Gaussian Copula method is adopted to form the joint probability distribution of market prices and develop an optimal low-carbon offering strategy. A sensitivity analysis of emission prices is conducted, to assess the impact of the carbon emission trading mechanism in the IES operation, considering a Henry Hub natural gas and ERCOT electricity market settlement. Simulation results illustrated, that the proposed approach can efficiently address possible price fluctuation uncertainties and that carbon emission trading, could stimulate wind penetration levels in the IES.

Nasiri et al. [96] introduced a stochastic bi-level optimization approach to analyze the impact of ESSs on a regional-local coupled electricity and natural gas market clearing. More specifically, the upper-level problem presents energy hub operator's (EHO) optimal scheduling, with the aim of minimizing purchasing costs of electricity and natural gas, whereas the objective function of the lower-level one, aims at clearing the coordinated electricity and natural gas market, considering wind power generation and the integration of linepack flexibility. Numerical analysis demonstrated that the adaptation of the multicarrier ESS can entail a significant drop of $7.01 \%$ and $1.7 \%$, on the daily operational cost of local and regional level, equivalently.

Finally, Baziar et al. [97] proposed a two-stage algorithm to derive optimal offering strategies for electricity and gas generators (EPs and GPs), under a coupled power and gas, day-ahead energy and reserve market settlement. At the first stage, a bi-level formulation is presented, pertaining to the minimization of strategic EPs' expected cost-revenue difference and the electricity market clearing problem, whereas at the second stage, the equivalent bilevel model for strategic GPs and natural gas market, is implemented. Demand and RESs' power uncertainty is modelled by stochastic programming, through a set of probabilityweighted scenarios. Numerical analysis emphasizes the computational efficiency of the proposed model and reports that, assets with low operation costs, tend to participate in the day-ahead energy market, while strategic EPs and GPs achieve a profit of $37.5 \%$ and $13.6 \%$, correspondingly, in their operational cost. However, the case of network congestion, which could offer more in-depth analysis, has not been studied.

\subsection{Market Equilibria}

\subsubsection{Electricity Market}

In case, when more than one participating agent acts strategically, EPEC modelling is employed. In particular, these models capture the interactions between market players and provide Nash equilibria, where each player is assumed to have full knowledge of the other players' equilibrium strategies. Ralph and Smeers [98] paved the way for modeling 
the interactions between strategic generators in deregulated electricity markets, in the form of equilibrium problems with equilibrium constraints (EPECs). Their work, based on the stationary theory of MPECs, introduced Nash stationary points to create sufficient conditions for finding pure Nash equilibria.

$\mathrm{Hu}$ and Ralph [99] developed a bi-level mathematical approach to model a noncooperative game in deregulated electricity markets with local marginal prices (LMPs), as an equilibrium program with equilibrium constraints (EPEC). Adequate conditions for the provision of pure-strategy Nash equilibria are established and certain applications are given. The model is implemented into a 39-bus network and the effects of transmission lines congestion on the existence of Nash equilibria is investigated. Several numerical examples were considered in order to detect Nash stationary points of arbitrarily engendered electricity market games. Yao et al. [100] formulated an optimization mathematical framework in the form of an EPEC to analyze the Nash-Cournot equilibrium, for two-settlement electricity markets, accounting for power flow congestion, demand load uncertainty, system contingencies and market power exertion. Results emphasized the efficiency of the proposed algorithms and their applicability in realistic contemporary power systems.

Pozo and Contreras [101] presented a fundamental stochastic multi-block bi-level mathematical model to derive pure-strategy Nash equilibria, in a pool-based electricity market environment, where generation companies behave as price-makers. Due to the assumption of inelastic demand, this objective function is homologous to the market's social welfare maximization. The solution of this problem generates spot prices and scheduled energy dispatch for each generation company, while an ex-post heuristic technique is proposed to reduce CPU computational requirements.

Ruiz et al. [102] developed a comprehensive bi-level single-period multi-block methodology to capture the interactions between several strategic producers, in a networkconstrained pool-based electricity market. The upper-level problem generates the optimal profit-maximizing strategies for each participating agent, subject to the day-ahead marketclearing conditions, derived by the lower-level optimization framework. Authors also provide market outcomes for four pool-based representations, i.e., a perfect competition market scheme, a monopoly and two independent duopoly environments, in order to compare the different LMPs, electricity dispatch and total expected profits, under each case. Numerical analysis highlighted the fact that a low degree of competition results in high prices, high generators' expected profits and low market social welfare. Sharma et al. [103] developed a stochastic Cournot formulation to obtain pure-strategy Nash equilibria and derive the optimal offering decisions for wind power producers acting strategically, in an oligopolistic day-ahead market and non-strategically in the balancing market. Wind generation uncertainty is modelled through a set of plausible scenarios, generated by the Auto Regressive Moving Average (ARMA) model. The proposed game-theoretic bidding approach is demonstrated via the implementation of two cases, i.e., a Base case, where WPPs do not consider rivals' behavior and a Stochastic Cournot case, in two different transmission-constrained power networks. Results indicate that the proposed Cournot model stimulates a significant profit increase over the Base case, while network congestions asymmetrically affect wind producers, depending on their power grid topology.

Kazempour and Zareipour [104] formulated an inspiring bi-level equilibrium approach to model a jointly cleared energy-only two-stage market and analyze the impacts of a large-scale wind power generator's integration in such an oligopolistic setting. In the first stage, ISO determines the day-ahead clearing price, producers' electricity dispatch and demand loads' consumption level. In the second stage, the balancing market is cleared for each wind generation scenario deriving balancing prices, wind power spillage, upward and downward reserve deployment and load curtailment. It is crucial to emphasize that a significant quota of this work's novelty, lies in the fact that wind farms can act strategically in both market settlements. Simulation results affirmed the efficiency of the proposed model in attaining pure-strategy Nash equilibria and illustrated that as wind power volatility increases, wind power spillage also rises, thus leading to wind producers' expected 
profits shrinkage. As anticipated, this generated an increment in dispatchable generators' profits, since they guarantee higher amounts of electricity and reserves.

Zou et al. [105] proposed an EPEC model to analyze electricity market equilibria, when three independently operated storage facilities, i.e., PHS, ZBFBS (zinc-bromine flow battery storage) and CAES, act strategically in a pool-based framework, among other dispatchable and non-dispatchable (hydro, wind, solar) generators. Numerical simulations for several case studies are conducted, including a benchmark case, where no storage facility is considered, and a strategic/competitive case for each storage agent. Results contain a comparative assessment of these three storage technologies and their impact on marketclearing prices, consumers' payments and their individual arbitrage expected profits. Dai and Qiao [106] considered a multi-period multi-block stochastic EPEC framework, to derive Nash equilibria in a short-term pool-based electricity market, characterized by assertive wind power penetration. A two-stage MPEC approach is employed to represent the strategic profit-making behavior of each wind power producer, in a sequentially cleared day-ahead and real-time market scheme. The model is implemented into a transmissionconstrained 6-bus network, while real-time demand information is acquired by the PJM market database. Subsequently, a concise analysis on the impact of different wind power penetration levels and possible network congestions and a comprehensive comparison between wind producers' strategic and non-strategic behavior, are performed.

Shahmohammadi et al. [107,108] introduced novel bi-level complementarity-based problems to model the interactions among a group of firms, which may operate a synthesis of dispatchable, non-dispatchable and energy storage facilities. The proposed algorithms are of the form of an EPEC, in which firms adopt a strategic behavior, that is, they simultaneously and individually yield their optimal profit-making offers into the market. Cases, in which electricity storage is owned by an independently operated profit-maximizing firm, an independently operated price-taking firm and a wind power generation firm are examined. Results demonstrate that possible co-ownership of energy storage by a wind generator leads to higher expected profits for the owner and lower total generation costs and market prices. Moreover, system inadequacies, such as wind power spillage and demand curtailment, caused by the wind power generation uncertainty, can be mitigated by the integration of energy storage agents in the market. However, the investigation of a network transmission congestion case constitutes an interesting extension of this problem.

Pandžić et al. [109] formulated a mathematical problem with equilibrium constraints, to analyze the participation and offering strategies of merchant-owned battery storage units (BSUs) in the day-ahead electricity market. The authors also address the case where multiple virtual storage plants (VSPs) compete for profit, developing an equilibrium problem with equilibrium constraints (EPEC). The proposed algorithm is applied to a modified IEEE RTS 96-bus power system and a comprehensive comparison between the coordinated (when all BSUs operate as a single VSP) and the uncoordinated case is accomplished. Gharibpour et al. [110] formulated a multi-stage multi-period stochastic equilibrium model to derive Nash equilibria and explore strategic players' participation in day-ahead and real-time pool-based markets, under net load uncertainty. Flexible ramp market is also considered, and the offers for flexible ramp up/down are submitted beside the optimal day-ahead offering strategies. The upper-level problem accounts for players profit maximization, whereas in the lower-level a sequential day-ahead and real-time market clearing process take place. Simulations results reveal that as the system's ramping requirements increase, ramping-capable assets are employed to dispatch electricity to the market, to a greater extent, compared to the others. Thus, firms owning such flexible assets tend to capitalize on critical profit increases.

Shafiekhani et al. [111] developed an equilibrium framework to derive the optimal bidding strategies for a VPP, consisting of conventional units, wind farms and interruptible loads, under a jointly cleared day-ahead electricity and regulation market scheme, in the presence of other strategic rival producers (GenCo). Power transfer distribution factors (PTDFs) are adopted to model network transmission constraints on an IEEE RTS and a 
diagonalization algorithm is proposed to obtain pure-strategy Nash equilibria. The authors alternatively address the current bi-level problem, employing the augmented $\varepsilon$-constrained method, which considers a bi-objective implementation, i.e., profit maximization and emissions minimization of VPP units. Simulation results reveal that profit and emission values in the bi-objective mode, are more reasonable, when compared to the initial singleobjective case.

Naebi et al. [112] formulated a bi-level optimization equilibrium framework to derive Nash equilibria among micro-grids, offering/bidding strategically in a day-ahead electricity market scheme. At the upper-level problem each micro-grid acts as a price-maker, while in the lower-level distribution network operator (DNO) collects the micro-grids' offers and clears the market, acting as a single follower. An ex-post approach, based on a diagonalization technique is employed, to investigate whether the obtained solutions of the EPEC model constitute Nash equilibria. Results' analysis indicates a reduction in distributed network costs and highlights the efficiency of the model in different market setups. The incorporation of the balancing market stage could be considered an interesting extension so that the problem can be studied even under uncertainty.

Recently, Tsimopoulos and Georgiadis [113] extended their previous contributions and presented a comprehensive approach to defining Nash equilibria in a pool-based networkconstrained electricity market. Market agents' offers are modelled through linear stepwise curves, while the stochastic nature of non-dispatchable generation is addressed, via the realization of possible wind power generation scenarios. A single-iteration diagonalization methodology is implemented to detect meaningful market equilibria and a 6-bus transmission constrained power system is employed to illustrate the applicability of the proposed algorithm. Numerical analysis emphasized the positive impact of producers' collusion on the increase in their expected profits and MCPs, in both congested and uncongested network cases.

Conjectural variations also constitute an effective way of modelling oligopolistic electricity market structures. Diaz et al. [114] introduced a novel iterative algorithm to estimate conjectured supply function (CSF) equilibria under inelastic system demand. The main contribution of this work though, is that for each electricity generator, competitors' strategies are initially concealed and endogenously computed by employing the proposed algorithm. The conjectures' estimation proves to be highly reliable and qualitative after having been tested in a series of different market situations. Ruiz et al. [115] recommended a mathematical approach in the form of a mixed linear complementarity problem, in order to analyze equilibria in electricity future and spot markets. Strategic generators reach through CV models to both rival players' production levels and spot prices. The model is characterized as a very useful tool to gain insights into the outcomes of the examined multi-market equilibrium.

Finally, Lagarto et al. [116] developed a CV model to evaluate the market power of electricity generators in the day-ahead market. In comparison to other corresponding methodologies, the $\mathrm{CV}$ model presents the advantage of assigning a share of competition to each agent, in each trading period. The proposed model is implemented in a case study considering the Iberian day-ahead market, to analyze the effects of Portuguese and Spanish electricity markets, on the generating agents' behavior.

\subsubsection{Coupling of Electricity and Natural Gas Markets}

Wang et al. [117] developed a state-of-the-art model to study coupled electricity and natural gas pool-based market equilibria, when each generator acts strategically, in order to maximize its expected profits. Two bi-level problems are presented, where the upperlevel problems account for profit maximization of strategic electricity and gas producers (SEP), (SGP) correspondingly, while the lower-levels represent the equivalent independent market clearing mechanism. A series of illustrative examples and case studies were used to illustrate the credibility the efficiency of the proposed approach, including a comparative analysis between the uncongested and the congested network cases for a large IEEE 118-bus 
power test system, accompanied by a 20-node natural gas system. Results indicate that SEPs and SGPs seek to capitalize on network congestion and bid higher prices, while the market operator aiming at maximizing social welfare, dispatches more conventional generation assets.

Chen et al. [118] introduced a fundamental bi-level optimization framework to analyze power and natural gas market Nash equilibria, attained by strategic firms who own a combined power and gas generation and demand portfolio and submit their profit-maximizing offers/bids to both market setups. At the upper level, the strategic actions of these firms seeking to exert market power, are presented, whereas the lower level consists of the electricity and gas market coupling, allowing perfect information interchange, though characterized by independent market-clearing mechanisms. Two case studies were used to capture market outcomes firms' behavior, under an electricity and gas market coupling settlement and examine the impact of network congestion on market efficiency and distributional outgrowth. Chen and Conejo [119] expanded this model implementing a thorough analysis and considering a multi-period equilibrium model to examine the interactions among strategic agents participating in electricity and natural gas markets. Hybrid and non-hybrid producers and consumers of electricity and natural gas are considered. A perfect and three oligopolistic competition models and the impact of gas-pressure limits on the market equilibria were systematically investigated. Results demonstrate that the gas system bottlenecks impact agents' expected profits, and the exercise of market power culminates in decreased social welfare. A synoptic classification of research contributions, based on the modelling approach used in each case, as well as their various market characteristics is presented in Table 1.

Table 1. Classification of research contributions based on their modelling approaches and market characteristics.

\begin{tabular}{cccccc}
\hline & $\begin{array}{c}\text { Modelling } \\
\text { Approach }\end{array}$ & $\begin{array}{c}\text { Conventional } \\
\text { Power Generation }\end{array}$ & $\begin{array}{c}\text { Integration of } \\
\text { Wind Power } \\
\text { Generation }\end{array}$ & $\begin{array}{c}\text { Integration of } \\
\text { Electricity Storage } \\
\text { Agents }\end{array}$ & $\begin{array}{c}\text { Electricity and } \\
\text { Natural Gas } \\
\text { Market Coupling }\end{array}$ \\
\cline { 2 - 6 } $\begin{array}{c}\text { Perfect } \\
\text { Competition }\end{array}$ & LP & {$[47]$} & {$[49,50,57]$} & {$[66-68,79,84,88]$} & {$[90,93,95]$} \\
\hline $\begin{array}{c}\text { Single Strategic } \\
\text { Generator }\end{array}$ & MLP & - & {$[59]$} & {$[65,71,77]$} & {$[94]$} \\
\hline \multirow{2}{*}{\begin{tabular}{c} 
Market Equilibria \\
\cline { 2 - 6 }
\end{tabular}} & EPEC & {$[41-46,48]$} & {$[52-56,58,60-63]$} & $\begin{array}{c}{[69,70,72-76,78,80-} \\
83,85,87]\end{array}$ & {$[13,91,92,96,97]$} \\
\hline
\end{tabular}

\section{Conclusions}

Optimization-based approaches, mainly linear and nonlinear programming as well as complementarity modelling, constitute nowadays the dominant means for dealing with complex electricity market problems, such as the pool clearing procedure and the determination of the optimal bidding strategies for generating agents, participating in a competitive market environment. These mathematical techniques seem to provide great modelling flexibility and versatility, sufficiently capture agents' interactions and incorporate various elements of game theory and economics.

In this review, we initially attempt a synoptic portrayal of the various energy market settlements worldwide and an explanatory disclosure of the market organization, fundamental operating principles, regulatory frameworks, compensation mechanisms and government policies and infrastructures. Consequently, a description of optimization algorithms that are currently employed in addressing contemporary problems related to the electricity market sector, is provided. In particular, the use of linear and nonlinear programming approaches to suitably model the clearing of the market under perfect competition is emphasized, as well as the employment of MPEC, EPEC and CV models, in 
order to capture the strategic behavior of a single or multiple players correspondingly, under an imperfect pool-based market setting.

Furthermore, the main purpose of this work is to provide an extensive literature review on the recent electricity pool-based market implementations and also highlight the effectiveness of the aforementioned optimization-based frameworks. In the context of this effort, research contributions, that propose alternative electricity market clearing mechanisms and investigate the integration of generating agents with renewable energy sources or electricity storage technologies portfolio into the existing framework, are designated. Particular emphasis is placed on the coupling of electricity and natural gas markets as well as the development of appropriate techniques to efficiently generate optimal offers/bids for strategic market players.

Although the majority of the above-analyzed fields have been thoroughly examined and a wide spectrum of models have been elaborated, resulting in interesting conclusions, some areas still deserve further study. A systematic evaluation of the operation of various storage technologies in a coupled electricity and natural gas market scheme constitutes an appealing prospect, to determine the technology that provides higher financial incentives and opportunities for a strategic player. Furthermore, relatively little progress has been made on the derivation of EPEC models, especially in the case of coupled markets, something that can be attributed to the mathematical and computational sophistication and complexity, of which they are characterized. Finally, the investigation of NGFPPs' optimal offers / bids seems to be a field of great research interest, since their double-edged nature allows them to act both as strategic generators and consumers, in electricity and natural gas markets equivalently.

Author Contributions: Conceptualization, C.N.D. and E.G.T.; methodology, E.G.T. and M.C.G.; validation, C.N.D., E.G.T. and M.C.G.; formal analysis, C.N.D.; investigation, C.N.D.; data curation, C.N.D.; writing—original draft preparation, C.N.D.; writing—review and editing, E.G.T. and M.C.G.; visualization, C.N.D.; supervision, M.C.G.; project administration, M.C.G. All authors have read and agreed to the published version of the manuscript.

Funding: This research received no external funding.

Institutional Review Board Statement: Not applicable.

Informed Consent Statement: Not applicable.

Conflicts of Interest: The authors declare no conflict of interest.

\section{References}

1. Kirschen, D.; Strbac, G. Fundamentals of Power System Economics; John Wiley \& Sons: Hoboken, NJ, USA, 2004. [CrossRef]

2. Stoft, S. Power System Economics: Designing Markets for Electricity; Wiley-IEEE Press: Piscataway, NJ, USA, 2002.

3. Australian Energy Market Operator. An Introduction to Australia's National Electricity Market. Energy Mark. Auth. Singapore, No. July 2010; p. 28. Available online: http://www.abc.net.au/mediawatch/transcripts/1234_aemo2.pdf (accessed on 7 May 2021).

4. AEMO. World's Leading Power System Operators Launch Global Consortium. Available online: https://aemo.com.au/ newsroom/news-updates/launch-of-global-consortium (accessed on 7 May 2021).

5. Pérez-Collazo, C.; Greaves, D.; Iglesias, G. A review of combined wave and offshore wind energy. Renew. Sustain. Energy Rev. 2015, 42, 141-153. [CrossRef]

6. Bessa, R.; Moreira, C.; Silva, B.; Matos, M. Handling renewable energy variability and uncertainty in power systems operation. Wiley Interdiscip. Rev. Energy Environ. 2013, 3, 156-178. [CrossRef]

7. IRENA. Global Energy Transformation: A Roadmap to 2050. 2019. Available online: https://www.irena.org/publications/2019 /Apr/Global-energy-transformation-A-roadmap-to-2050-2019Edition (accessed on 7 May 2021).

8. IRENA. Electricity Storage Valuation Framework: Assessing System Value and Ensuring Project Viability. 2020. Available online: https:/ /irena.org/publications/2020/Mar/Electricity-Storage-Valuation-Framework-2020 (accessed on 7 May 2021).

9. IRENA. Electricity Storage and Renewables: Costs and Markets to 2030. October 2017. Available online: https://www.irena.org/ publications/2017/oct/electricity-storage-and-renewables-costs-and-markets (accessed on 7 May 2021).

10. Commision for Energy Regulation. Review of Competition in the Electricity and Gas Retail Markets Executive Summary. 2017. Available online: https:/ /www.cru.ie/wp-content/uploads/2017/07/CER17019-Review-of-Competition-in-the-Electricityand-Gas-Retail-Markets-1.pdf (accessed on 7 May 2021). 
11. Comisión Europea. Quinto Informe sobre el estado de la Unión de la Energía. Inf. Com. Eur. 2020. Available online: https:/ / eur-lex.europa.eu/legal-content/EN/TXT/?uri=COM:2020:0950:FIN (accessed on 7 May 2021).

12. ACER. Annual Report on the Results of Monitoring the Internal Electricity and Natural Gas Markets in 2014. 2015. Available online: https:/ / documents.acer.europa.eu/Official_documents/Acts_of_the_Agency/Publication/ACER_Market_Monitoring_ Report_2014.pdf (accessed on 7 May 2021).

13. Duenas, P.; Leung, T.; Gil, M.; Reneses, J. Gas-Electricity Coordination in Competitive Markets Under Renewable Energy Uncertainty. IEEE Trans. Power Syst. 2014, 30, 123-131. [CrossRef]

14. Babula, M.; Petak, K. The Cold Truth: Managing Gas-Electric Integration: The ISO New England Experience. IEEE Power Energy Mag. 2014, 12, 20-28. [CrossRef]

15. Biskas, P.; Kanelakis, N.; Papamatthaiou, A.; Alexandridis, I. Coupled optimization of electricity and natural gas systems using augmented Lagrangian and an alternating minimization method. Int. J. Electr. Power Energy Syst. 2016, 80, 202-218. [CrossRef]

16. Ordoudis, C.; Pinson, P.; Morales, J.M. An Integrated Market for Electricity and Natural Gas Systems with Stochastic Power Producers. Eur. J. Oper. Res. 2019, 272, 642-654. [CrossRef]

17. González, P.; Villar, J.; Díaz, C.A.; Campos, F.A. Joint energy and reserve markets: Current implementations and modeling trends. Electr. Power Syst. Res. 2014, 109, 101-111. [CrossRef]

18. Karthikeyan, S.P.; Raglend, I.J.; Kothari, D. A review on market power in deregulated electricity market. Int. J. Electr. Power Energy Syst. 2013, 48, 139-147. [CrossRef]

19. Ruiz, C.; Conejo, A.J.; Fuller, J.D.; Gabriel, S.A.; Hobbs, B.F. A tutorial review of complementarity models for decision-making in energy markets. EURO J. Decis. Process. 2014, 2, 91-120. [CrossRef]

20. Behrangrad, M. A review of demand side management business models in the electricity market. Renew. Sustain. Energy Rev. 2015, 47, 270-283. [CrossRef]

21. Sharifi, R.; Fathi, S.; Vahidinasab, V. A review on Demand-side tools in electricity market. Renew. Sustain. Energy Rev. 2017, 72, 565-572. [CrossRef]

22. Aghaei, J.; Alizadeh, M.-I. Demand response in smart electricity grids equipped with renewable energy sources: A review. Renew. Sustain. Energy Rev. 2013, 18, 64-72. [CrossRef]

23. Naval, N.; Yusta, J.M. Virtual power plant models and electricity markets-A review. Renew. Sustain. Energy Rev. 2021, 149, 111393. [CrossRef]

24. Yin, S.; Wang, J.; Li, Z.; Fang, X. State-of-the-art short-term electricity market operation with solar generation: A review. Renew. Sustain. Energy Rev. 2020, 138, 110647. [CrossRef]

25. Singh, A.; Parida, S. A review on distributed generation allocation and planning in deregulated electricity market. Renew. Sustain. Energy Rev. 2018, 82, 4132-4141. [CrossRef]

26. Conejo, A.J.; Carrión, M.; Morales, J.M. Decision Making Under Uncertainty in Electricity Markets; Springer: Berlin/Heidelberg, Germany, 2010. [CrossRef]

27. Morales, J.M.; Conejo, A.J.; Madsen, H.; Pinson, P.; Zugno, M. Integrating Renewables in Electricity Markets; Springer: Berlin/Heidelberg, Germany, 2014. [CrossRef]

28. Gan, D.; Feng, D.; Xie, J. Electricity Markets and Power System Economics; CRC Press: Boca Raton, FL, USA, 2013. [CrossRef]

29. Sioshansi, F.P. Competitive Electricity Markets: Questions Remain about Design, Implementation, Performance. Electr. J. 2008, 21, 74-87. [CrossRef]

30. Tierney, S.; Schatzki, T.; Mukerji, R. Uniform-Pricing versus Pay-as-Bid in Wholesale Electricity Markets: Does It Make a Difference? ISO: New York, NY, USA, 2008.

31. Vega-Redondo, F. Economics and the Theory of Games; Cambridge University Press: Cambridge, UK, 2003. [CrossRef]

32. Conejo, A.J.; Ruiz, C. Complementarity, Not Optimization, is the Language of Markets. IEEE Open Access J. Power Energy 2020, 7, 344-353. [CrossRef]

33. Díaz, C.A.; Villar, J.; Campos, F.A.; Reneses, J. Electricity market equilibrium based on conjectural variations. Electr. Power Syst. Res. 2010, 80, 1572-1579. [CrossRef]

34. Devine, M.; Siddiqui, S. Modelling an electricity market oligopoly with a competitive fringe and generation investments. arXiv 2020, arXiv:2001.03526.

35. Chen, Y.; Hobbs, B.F.; Leyffer, S.; Munson, T.S. Leader-Follower Equilibria for Electric Power and NO x Allowances Markets. Comput. Manag. Sci. 2006, 3, 307-330. [CrossRef]

36. Fortuny-Amat, J.; McCarl, B. A Representation and Economic Interpretation of a Two-Level Programming Problem. J. Oper. Res. Soc. 1981, 32, 783. [CrossRef]

37. Pereira, M.; Granville, S.; Fampa, M.; Dix, R.; Barroso, L. Strategic Bidding Under Uncertainty: A Binary Expansion Approach. IEEE Trans. Power Syst. 2005, 20, 180-188. [CrossRef]

38. Conejo, A.J.; Castillo, R.M.E.; García-bertrand, R. Decomposition Techniques in Mathematical Programming; Springer: Berlin/Heidelberg, Germany, 2006.

39. Gabriel, S.A.; Conejo, A.J.; Fuller, J.D.; Hobbs, B.F.; Ruiz, C. Complementarity Modeling in Energy Markets; Springer: Berlin/Heidelberg, Germany, 2013. [CrossRef]

40. Pozo, D.; Sauma, E.; Contreras, J. Basic theoretical foundations and insights on bilevel models and their applications to power systems. Ann. Oper. Res. 2017, 254, 303-334. [CrossRef] 
41. Ruiz, C.; Conejo, A. Pool Strategy of a Producer with Endogenous Formation of Locational Marginal Prices. IEEE Trans. Power Syst. 2009, 24, 1855-1866. [CrossRef]

42. Gabriel, S.A.; Leuthold, F.U. Solving discretely-constrained MPEC problems with applications in electric power markets. Energy Econ. 2010, 32, 3-14. [CrossRef]

43. Ruiz, C.; Conejo, A.; Gabriel, S.A. Pricing Non-Convexities in an Electricity Pool. IEEE Trans. Power Syst. 2012, 27, 1334-1342. [CrossRef]

44. Ruiz, C.; Conejo, A.J.; Bertsimas, D.J. Prices Via Inverse Optimization. IEEE Power Syst. 2013, 28, 3056-3064. [CrossRef]

45. Kardakos, E.G.; Simoglou, C.K.; Bakirtzis, A. Optimal bidding strategy in transmission-constrained electricity markets. Electr. Power Syst. Res. 2014, 109, 141-149. [CrossRef]

46. Kardakos, E.G.; Simoglou, C.K.; Bakirtzis, A.G. Optimal Offering Strategy of a Virtual Power Plant: A Stochastic Bi-Level Approach. IEEE Trans. Smart Grid 2015, 7, 794-806. [CrossRef]

47. Mazzi, N.; Kazempour, J.; Pinson, P. Price-Taker Offering Strategy in Electricity Pay-as-Bid Markets. IEEE Trans. Power Syst. 2017, 33, 2175-2183. [CrossRef]

48. Porras-Ortiz, F.; Añó, O.; Rubio-Barros, R.; Weber, C. Energy and reserve strategic offers in regional electricity markets: A complementarity approach. Int. J. Electr. Power Energy Syst. 2020, 119, 105860. [CrossRef]

49. Morales, J.; Conejo, A.; Ruiz, J.P. Short-Term Trading for a Wind Power Producer. IEEE Trans. Power Syst. 2010, 25, 554-564. [CrossRef]

50. Morales, J.; Conejo, A.; Liu, K.; Zhong, J. Pricing Electricity in Pools with Wind Producers. IEEE Trans. Power Syst. 2012, 27, 1366-1376. [CrossRef]

51. Grigg, C.; Wong, P.; Albrecht, P.; Allan, R.; Bhavaraju, M.; Billinton, R.; Chen, Q.; Fong, C.; Haddad, S.; Kuruganty, S.; et al. The IEEE Reliability Test System-1996. A report prepared by the Reliability Test System Task Force of the Application of Probability Methods Subcommittee. IEEE Trans. Power Syst. 1999, 14, 1010-1020. [CrossRef]

52. Baringo, L.; Conejo, A. Strategic Offering for a Wind Power Producer. IEEE Trans. Power Syst. 2013, 28, 4645-4654. [CrossRef]

53. Zugno, M.; Morales, J.; Pinson, P.; Madsen, H. Pool Strategy of a Price-Maker Wind Power Producer. IEEE Trans. Power Syst. 2013, 28, 3440-3450. [CrossRef]

54. Pandžić, H.; Morales, J.M.; Conejo, A.J.; Kuzle, I. Offering model for a virtual power plant based on stochastic programming. Appl. Energy 2013, 105, 282-292. [CrossRef]

55. Delikaraoglou, S.; Papakonstantinou, A.; Ordoudis, C.; Pinson, P. Price-maker wind power producer participating in a joint day-ahead and real-time market. Int. Conf. Eur. Energy Mark. EEM 2015, 2015, 1-5. [CrossRef]

56. Dai, T.; Qiao, W. Optimal Bidding Strategy of a Strategic Wind Power Producer in the Short-Term Market. IEEE Trans. Sustain. Energy 2015, 6, 707-719. [CrossRef]

57. Reddy, S.S.; Bijwe, P.; Abhyankar, A. Optimum day-ahead clearing of energy and reserve markets with wind power generation using anticipated real-time adjustment costs. Int. J. Electr. Power Energy Syst. 2015, 71, 242-253. [CrossRef]

58. Exizidis, L.; Kazempour, J.; Pinson, P.; De Greve, Z.; Vallee, F. Strategic wind power trading considering rival wind power production. In Proceedings of the 2016 IEEE Innovative Smart Grid Technologies-Asia (ISGT-Asia), Melbourne, VIC, Australia, 28 November-1 December 2016; pp. 873-878. [CrossRef]

59. Soares, T.; Jensen, T.V.; Mazzi, N.; Pinson, P.; Morais, H. Optimal offering and allocation policies for wind power in energy and reserve markets. Wind. Energy 2017, 20, 1851-1870. [CrossRef]

60. Tsimopoulos, E.G.; Georgiadis, M.C. Strategic offers in day-ahead market co-optimizing energy and reserve under high penetration of wind power production: An MPEC approach. AIChE J. 2018, 65, e16495. [CrossRef]

61. Tsimopoulos, E.G.; Georgiadis, M.C. Optimal strategic offerings for a conventional producer in jointly cleared energy and balancing markets under high penetration of wind power production. Appl. Energy 2019, 244, 16-35. [CrossRef]

62. Tsimopoulos, E.G.; Georgiadis, M.C. Withholding strategies for a conventional and wind generation portfolio in a joint energy and reserve pool market: A gaming-based approach. Comput. Chem. Eng. 2019, 134, 106692. [CrossRef]

63. Rintamäki, T.; Siddiqui, A.S.; Salo, A. Strategic offering of a flexible producer in day-ahead and intraday power markets. Eur. J. Oper. Res. 2020, 284, 1136-1153. [CrossRef]

64. Kazempour, S.J.; Yousefi, A.; Zare, K.; Moghaddam, M.P.; Haghifam, M.; Yousefi, G. A MIP-based optimal operation scheduling of pumped-storage plant in the energy and regulation markets. In Proceedings of the 2008 43rd International Universities Power Engineering Conference, Padua, Italy, 1-4 September 2008; pp. 1-5. [CrossRef]

65. Kanakasabapathy, P.; Swarup, K.S. Bidding strategy for pumped-storage plant in pool-based electricity market. Energy Convers. Manag. 2010, 51, 572-579. [CrossRef]

66. Drury, E.; Denholm, P.; Sioshansi, R. The value of compressed air energy storage in energy and reserve markets. Energy 2011, 36, 4959-4973. [CrossRef]

67. Akhavan-Hejazi, H.; Mohsenian-Rad, H. Optimal Operation of Independent Storage Systems in Energy and Reserve Markets with High Wind Penetration. IEEE Trans. Smart Grid 2013, 5, 1088-1097. [CrossRef]

68. Akhavan-Hejazi, H.; Asghari, B.; Sharma, R.K. A joint bidding and operation strategy for battery storage in multi-temporal energy markets. In Proceedings of the 2015 IEEE Power \& Energy Society Innovative Smart Grid Technologies Conference (ISGT), Washington, DC, USA, 18-20 February 2015; pp. 1-5. [CrossRef]

69. Awad, A.S.A.; Fuller, J.D.; El-Fouly, T.; Salama, M.M.A. Impact of Energy Storage Systems on Electricity Market Equilibrium. IEEE Trans. Sustain. Energy 2014, 5, 875-885. [CrossRef] 
70. Pandzic, H.; Kuzle, I. Energy storage operation in the day-ahead electricity market. In Proceedings of the 201512 th International Conference on the European Energy Market (EEM), Lisbon, Portugal, 19-22 May 2015; pp. 1-6. [CrossRef]

71. Ding, H.; Pinson, P.; Hu, Z.; Song, Y. Integrated Bidding and Operating Strategies for Wind-Storage Systems. IEEE Trans. Sustain. Energy 2015, 7, 163-172. [CrossRef]

72. Mohsenian-Rad, H. Coordinated Price-Maker Operation of Large Energy Storage Units in Nodal Energy Markets. IEEE Trans. Power Syst. 2015, 31, 786-797. [CrossRef]

73. Nasrolahpour, E.; Kazempour, J.; Zareipour, H.; Rosehart, W.D. Strategic Sizing of Energy Storage Facilities in Electricity Markets. IEEE Trans. Sustain. Energy 2016, 7, 1462-1472. [CrossRef]

74. Nasrolahpour, E.; Zareipour, H.; Rosehart, W.D.; Kazempour, J. Bidding strategy for an energy storage facility. In Proceedings of the 2016 Power Systems Computation Conference (PSCC), Genoa, Italy, 20-24 June 2016; pp. 1-7. [CrossRef]

75. Nasrolahpour, E.; Kazempour, J.; Zareipour, H.; Rosehart, W.D. A Bilevel Model for Participation of a Storage System in Energy and Reserve Markets. IEEE Trans. Sustain. Energy 2017, 9, 582-598. [CrossRef]

76. Ye, Y.; Papadaskalopoulos, D.; Strbac, G. An MPEC approach for analysing the impact of energy storage in imperfect electricity markets. In Proceedings of the 2016 13th International Conference on the European Energy Market (EEM), Porto, Portugal, 6-9 June 2016; pp. 1-5. [CrossRef]

77. He, G.; Chen, Q.; Kang, C.; Pinson, P.; Xia, Q. Optimal Bidding Strategy of Battery Storage in Power Markets Considering Performance-Based Regulation and Battery Cycle Life. IEEE Trans. Smart Grid 2015, 7, 2359-2367. [CrossRef]

78. Contereras-Ocana, J.E.; Wang, Y.; Ortega-Vazquez, M.A.; Zhang, B. Energy storage: Market power and social welfare. In Proceedings of the 2017 IEEE Power \& Energy Society General Meeting, Chicago, IL, USA, 16-20 July 2017; pp. 1-5. [CrossRef]

79. Ding, H.; Pinson, P.; Hu, Z.; Wang, J.; Song, Y. Optimal Offering and Operating Strategy for a Large Wind-Storage System as a Price Maker. IEEE Trans. Power Syst. 2017, 32, 4904-4913. [CrossRef]

80. Vespermann, N.; Delikaraoglou, S.; Pinson, P. Offering strategy of a price-maker energy storage system in day-ahead and balancing markets. In Proceedings of the 2017 IEEE Manchester PowerTech, Manchester, UK, 18-22 June 2017; pp. 1-6. [CrossRef]

81. Wang, Y.; Dvorkin, Y.; Fernandez-Blanco, R.; Xu, B.; Qiu, T.; Kirschen, D.S. Look-Ahead Bidding Strategy for Energy Storage. IEEE Trans. Sustain. Energy 2017, 8, 1106-1117. [CrossRef]

82. Wang, Y.; Dvorkin, Y.; Fernández-Blanco, R.; Xu, B.; Kirschen, D.S. Impact of local transmission congestion on energy storage arbitrage opportunities. arXiv 2017, arXiv:1702.04816v1.

83. Ye, Y.; Papadaskalopoulos, D.; Moreira, R.; Strbac, G. Strategic capacity withholding by energy storage in electricity markets. In Proceedings of the 2017 IEEE Manchester PowerTech, Manchester, UK , 18-22 June 2017; pp. 1-6. [CrossRef]

84. Nojavan, S.; Najafi-Ghalelou, A.; Majidi, M.; Zare, K. Optimal bidding and offering strategies of merchant compressed air energy storage in deregulated electricity market using robust optimization approach. Energy 2018, 142, 250-257. [CrossRef]

85. Schillemans, A.; Serrano, G.D.V.; Bruninx, K. Strategic Participation of Merchant Energy Storage in Joint Energy-Reserve and Balancing Markets. IET Conf. Publ. 2018, 88, CP759. [CrossRef]

86. Bruninx, K.; Delarue, E. Endogenous Probabilistic Reserve Sizing and Allocation in Unit Commitment Models: Cost-Effective, Reliable, and Fast. IEEE Trans. Power Syst. 2016, 32, 2593-2603. [CrossRef]

87. Tómasson, E.; Hesamzadeh, M.R.; Wolak, F.A. Optimal offer-bid strategy of an energy storage portfolio: A linear quasi-relaxation approach. Appl. Energy 2019, 260, 114251. [CrossRef]

88. Khatami, R.; Oikonomou, K.; Parvania, M. Look-Ahead Optimal Participation of Compressed Air Energy Storage in Day-Ahead and Real-Time Markets. IEEE Trans. Sustain. Energy 2019, 11, 682-692. [CrossRef]

89. Khaloie, H.; Abdollahi, A.; Shafie-Khah, M.; Anvari-Moghaddan, A.; Nojavan, S.; Siano, P.; Catalão, J.P.S. Coordinated windthermal-energy storage offering strategy in energy and spinning reserve markets using a multi-stage model. Appl. Energy 2019, 259, 114168. [CrossRef]

90. Gil, M.; Duenas, P.; Reneses, J. Electricity and Natural Gas Interdependency: Comparison of Two Methodologies for Coupling Large Market Models Within the European Regulatory Framework. IEEE Trans. Power Syst. 2015, 31, 361-369. [CrossRef]

91. Ordoudis, C.; Delikaraoglou, S.; Pinson, P.; Kazempour, J. Exploiting flexibility in coupled electricity and natural gas markets: A price-based approach. In Proceedings of the 2017 IEEE Manchester PowerTech, Manchester, UK, 18-22 June 2017; pp. 1-6. [CrossRef]

92. Ordoudis, C.; Delikaraoglou, S.; Kazempour, J.; Pinson, P. Market-based coordination of integrated electricity and natural gas systems under uncertain supply. Eur. J. Oper. Res. 2020, 287, 1105-1119. [CrossRef]

93. Chen, R.; Wang, J.; Sun, H. Clearing and Pricing for Coordinated Gas and Electricity Day-Ahead Markets Considering Wind Power Uncertainty. IEEE Trans. Power Syst. 2017, 33, 2496-2508. [CrossRef]

94. Zhao, B.; Zlotnik, A.; Conejo, A.J.; Sioshansi, R.; Rudkevich, A.M. Shadow Price-Based Co-Ordination of Natural Gas and Electric Power Systems. IEEE Trans. Power Syst. 2018, 34, 1942-1954. [CrossRef]

95. Yan, Y.; Lin, Z.; Wen, F.; Palu, I.; Chen, X.; Zheng, W.; Zhang, L. Optimal Operation Strategy for an Integrated Low-Carbon Energy System in Coupled Electricity and Natural Gas Markets. IEEE Trans. Power Syst. 2019, 34, 3696-3701. [CrossRef]

96. Nasiri, N.; Yazdankhah, A.S.; Mirzaei, M.A.; Loni, A.; Mohammadi-Ivatloo, B.; Zare, K.; Marzband, M. A bi-level market-clearing for coordinated regional-local multi-carrier systems in presence of energy storage technologies. Sustain. Cities Soc. 2020, 63, 102439. [CrossRef]

97. Baziar, A.A.; Niknam, T.; Simab, M. Strategic offering of producers in the day-ahead coupled gas and electricity market including energy and reserve models. Electr. Power Syst. Res. 2021, 199, 107376. [CrossRef] 
98. Ralph, D.; Smeers, Y. EPECs as models for electricity markets. In Proceedings of the 2006 IEEE PES Power Systems Conference and Exposition, Atlanta, GA, USA, 29 October-1 November 2006; pp. 74-80. [CrossRef]

99. Hu, X.; Ralph, D. Using EPECs to Model Bilevel Games in Restructured Electricity Markets with Locational Prices. Oper. Res. 2007, 55, 809-827. [CrossRef]

100. Yao, J.; Adler, I.; Oren, S.S. Modeling and Computing Two-Settlement Oligopolistic Equilibrium in a Congested Electricity Network. Oper. Res. 2008, 56, 34-47. [CrossRef]

101. Pozo, D.; Contreras, J. Finding Multiple Nash Equilibria in Pool-Based Markets: A Stochastic EPEC Approach. IEEE Trans. Power Syst. 2011, 26, 1744-1752. [CrossRef]

102. Ruiz, C.; Conejo, A.; Smeers, Y. Equilibria in an Oligopolistic Electricity Pool with Stepwise Offer Curves. IEEE Trans. Power Syst. 2011, 27, 752-761. [CrossRef]

103. Sharma, K.; Bhakar, R.; Tiwari, H. Strategic bidding for wind power producers in electricity markets. Energy Convers. Manag. 2014, 86, 259-267. [CrossRef]

104. Kazempour, S.J.; Zareipour, H. Equilibria in an Oligopolistic Market with Wind Power Production. IEEE Trans. Power Syst. 2013, 29, 686-697. [CrossRef]

105. Zou, P.; Chen, Q.; Xia, Q.; He, G.; Kang, C.; Conejo, A.J. Pool equilibria including strategic storage. Appl. Energy 2016, 177, 260-270. [CrossRef]

106. Dai, T.; Qiao, W. Finding Equilibria in the Pool-Based Electricity Market with Strategic Wind Power Producers and Network Constraints. IEEE Trans. Power Syst. 2016, 32, 389-399. [CrossRef]

107. Shahmohammadi, A.; Sioshansi, R.; Conejo, A.; Afsharnia, S. Market equilibria and interactions between strategic generation, wind, and storage. Appl. Energy 2018, 220, 876-892. [CrossRef]

108. Shahmohammadi, A.; Sioshansi, R.; Conejo, A.; Afsharnia, S. The role of energy storage in mitigating ramping inefficiencies caused by variable renewable generation. Energy Convers. Manag. 2018, 162, 307-320. [CrossRef]

109. Pandžić, K.; Pandžić, H.; Kuzle, I. Virtual storage plant offering strategy in the day-ahead electricity market. Int. J. Electr. Power Energy Syst. 2018, 104, 401-413. [CrossRef]

110. Gharibpour, H.; Aminifar, F. Multi-stage equilibrium in electricity pool with flexible ramp market. Int. J. Electr. Power Energy Syst. 2019, 109, 661-671. [CrossRef]

111. Shafiekhani, M.; Badri, A.; Shafie-Khah, M.; Catalão, J.P. Strategic bidding of virtual power plant in energy markets: A bi-level multi-objective approach. Int. J. Electr. Power Energy Syst. 2019, 113, 208-219. [CrossRef]

112. Naebi, A.; SeyedShenava, S.; Contreras, J.; Ruiz, C.; Akbarimajd, A. EPEC approach for finding optimal day-ahead bidding strategy equilibria of multi-microgrids in active distribution networks. Int. J. Electr. Power Energy Syst. 2019, 117, 105702. [CrossRef]

113. Tsimopoulos, E.G.; Georgiadis, M.C. Nash equilibria in electricity pool markets with large-scale wind power integration. Energy 2021, 228, 120642. [CrossRef]

114. Díaz, C.A.; Villar, J.; Campos, F.A.; Rodríguez, M. A new algorithm to compute conjectured supply function equilibrium in electricity markets. Electr. Power Syst. Res. 2010, 81, 384-392. [CrossRef]

115. Ruiz, C.; Kazempour, J.; Conejo, A.J. Equilibria in futures and spot electricity markets. Electr. Power Syst. Res. 2012, 84, 1-9. [CrossRef]

116. Lagarto, J.; Sousa, J.A.; Martins, Á.; Ferrão, P. Market power analysis in the Iberian electricity market using a conjectural variations model. Energy 2014, 76, 292-305. [CrossRef]

117. Wang, C.; Wei, W.; Wang, J.; Liu, F.; Mei, S. Strategic Offering and Equilibrium in Coupled Gas and Electricity Markets. IEEE Trans. Power Syst. 2017, 33, 290-306. [CrossRef]

118. Chen, S.; Conejo, A.J.; Sioshansi, R.; Wei, Z. Equilibria in Electricity and Natural Gas Markets with Strategic Offers and Bids. IEEE Trans. Power Syst. 2019, 35, 1956-1966. [CrossRef]

119. Chen, S.; Conejo, A.J. Strategic-Agent Equilibria in the Operation of Natural Gas and Power Markets. Energies 2020, 13, 868. [CrossRef] 